\title{
Absorbing aerosols facilitate transition of Indian monsoon breaks to active spells
}

\author{
M. G. Manoj • P. C. S. Devara · P. D. Safai • \\ B. N. Goswami
}

Received: 6 May 2010/ Accepted: 18 December 2010/Published online: 31 December 2010

(C) Springer-Verlag 2010

\begin{abstract}
While some long breaks of monsoon intraseasonal oscillations (MISOs) are followed by active spells (BFA), some others are not (BNFA). The circulation during BFA (BNFA) cases helps (prevents) accumulation of absorbing aerosols over central India (CI) resulting in almost three times larger Aerosol Index (AI) over CI, during BFA cases compared to BNFA cases. A seminal role played by the absorbing aerosols in the transition from break to active spells is unraveled through modification of the north-south temperature gradient at lower levels. The meridional gradient of temperature at low level $(\Delta T)$ between aerosol-rich $\mathrm{CI}$ and pristine equatorial Indian Ocean is large $\left(>6^{\circ} \mathrm{C}\right)$ and sustains for long time ( $>10$ days) during BFA leading to significant moisture convergence to $\mathrm{CI}$. The stability effect arising from surface cooling by the aerosols is overcome by the enhanced moisture convergence creating a moist static unstable atmosphere conducive for the large-scale organized convection over the CI region leading to the resurgence of active spells. The moisture convergence induced by $\Delta T$ was also able to overcome possible aerosol indirect effect (Twomey effect) and initiate deep convection and transition to active condition. During BNFA cases,
\end{abstract}

\footnotetext{
M. G. Manoj $(\bowtie)$ · P. C. S. Devara · P. D. Safai ·

B. N. Goswami

Indian Institute of Tropical Meteorology,

Pashan, Pune 411 008, India

e-mail: mgmanoj@tropmet.res.in

P. C. S. Devara

e-mail: devara@tropmet.res.in

P. D. Safai

e-mail: pdsafai@tropmet.res.in

B. N. Goswami

e-mail: goswami@tropmet.res.in
}

however the maximum $\Delta T$, which was weaker than the BFA cases by more than $1.5^{\circ} \mathrm{C}$, could not sustain required moisture convergence and failed to lead to a sustained active spell. Using data from MODIS (MODerate resolution Imaging Spectroradiometer) onboard Terra and several other input parameters from various satellites for the period 2000-2009, the aerosol induced radiative forcing representative of two regions-the CI to the north and the pristine ocean to the south-were estimated and support the differences in observed $\Delta T$ during the two cases. Our results highlight the need for proper inclusion of absorbing aerosols in dynamical models for simulation of the observed variability of MISOs and their extended range prediction.

Keywords Aerosols - Radiative forcing - Indian summer monsoon · Intraseasonal oscillation · Regional climate

\section{Introduction}

The sub-seasonal oscillations with time scales longer than synoptic but shorter than seasonal, known as intraseasonal variability (ISV), have emerged as the primary building block for the Indian summer monsoon (ISM). The ISV manifests as 'active' and inactive or 'break' spells within the monsoon season that have tremendous impact on agricultural production, water resource management, and other weather-sensitive industries. The importance of the ISV arises from the realization that while on one hand it influences predictability of the seasonal mean climate (Goswami and Ajaya Mohan 2001), it also influences weather predictability by modulating the frequency of occurrence of synoptic events such as lows, depressions and tropical cyclones (Maloney and Hartmann 2000; 
Goswami et al. 2003). The amplitude of ISV is much larger than that of the interannual variability (IAV) of the seasonal mean and comparable to that of the seasonal cycle (Waliser 2006), thus providing optimism for extended range prediction. Quantitative estimates of potential predictability of ISV (Waliser et al. 2003; Goswami and Xavier 2003) indicate that the limit of useful skill of predicting the active-break spells may be extended to 25-30 days. High potential usefulness of intraseasonal forecasts for agriculture, society and economy has triggered a number of research activities to develop empirical as well as dynamical models for extended range prediction of monsoon ISV. During the past few years, several studies (Waliser et al. 1999; Mo 2001; Goswami and Xavier 2003; Webster and Hoyos 2004; Jones et al. 2004) have demonstrated the feasibility of predicting the active-break spells of ISM 20-25 days in advance. These models, however, could not be effectively used for real time operational forecasting due to nature of time filters involved in constructing the empirical models.

Progress in understanding the origin and propagation characteristics of monsoon ISV during the past two decades (see Goswami 2005 for a review) has led to the discovery of an analogue technique for real time forecasting of active-break spells of ISM (Xavier and Goswami 2007; Chattopadhyay et al. 2008). While the existence of an underlying oscillatory mode provides the basis for predictability of the ISV, the prediction skill of the models is limited by existence of significant event-to-event variability in amplitude as well as its evolution characteristics. If the event-to-event variability of the ISV is entirely due to dynamic nonlinearity of the phenomenon, we may not be able to do much in way of improving prediction skill of the models. However, the prediction skill of the models may have a chance for improvement if the event-to-event variability is due to some known forcing. Here, we propose that a part of this variability arises from interactions with aerosols through direct radiative forcing.

The Asian monsoon region is known to have high concentration of anthropogenic aerosols which significantly influence the regional climate through direct radiative forcing (Ramanathan and Carmichael 2008; Pandithurai et al. 2008; Jayaraman 2001). As a result, the role of such aerosols on the Indian monsoon hydrological cycle has been a subject of intense ongoing investigation (Rahul et al. 2008). Some initial studies (Rosenfeld 2000; Menon et al. 2002; Ramanathan et al. 2005) indicated that Indian monsoon may weaken as a result of these aerosols through cooling the land and weakening the north south surface temperature gradients. Other studies (Lau and Kim 2006; Lau et al. 2006) indicated that due to the absorbing nature of some of these aerosols, they may strengthen the monsoon and increase June-July rainfall through the elevated heat pump mechanism. Using time-evolving global distributions of black carbon aerosols in a global coupled climate model (CCSM-3), Meehl et al. (2008) show that such aerosols lead to increase in pre-monsoon (March-April-May) rainfall while tend to decrease monsoon (June-July-August) rainfall over the Indian region. Collier and Zhang (2009) revisited the aerosol forcing of Indian monsoon simulated by the NCAR community atmosphere model (CAM3) by providing time varying three dimensional mass distribution of aerosols (through the GOCART model). They find that while the aerosols increase the precipitation during the premonsoon months (April-May), they tend to decrease precipitation during monsoon (June-July). Thus, the response of the Indian monsoon to aerosol does depend on the way the aerosols are treated in the model and fidelity of the model to simulate the observed monsoon climate. While a large number of such studies have addressed the question of possible influence of the aerosols on the seasonal mean climate, how the aerosols may modify the monsoon ISV (active-break cycles) has not been addressed.

Do we expect the aerosols to influence the monsoon ISV? While the aerosol concentration has a seasonal cycle with high concentration during winter and pre-monsoon months and lower concentration during monsoon season due to wash out effect (Devara et al. 2003; Tripathi et al. 2006), as measured by an instrumented aircraft during our CAIPEEX (Cloud Aerosol Interaction and Precipitation Enhancement Experiment, see the URL: http://www. tropmet.res.in/ caipeex) Phase-I in 2009, significant concentration of black carbon is seen even during monsoon season between 1 and $3 \mathrm{~km}$ (Fig. 1) over the continental region. Figure 1a shows the vertical profile of black carbon (BC) aerosols measured by an Aethalometer during CAIPEEX Phase-I over Hyderabad in central India on June 21, 2009, when there had been prevalence of a break situation. Figure $1 \mathrm{~b}$ also illustrates the vertical profile of $\mathrm{BC}$ but for another location Guwahati in the north-east India on 06 September, 2009. This day happened to fall within a normal monsoon day for central India (CI), which generally corresponds to a break condition for the north-east India. High loading of BC between 1 and $3 \mathrm{~km}$ is observed over both the stations. Therefore, the direct radiative effects of these aerosols could influence the evolution of the activebreak cycles through modification of the spatial distribution of the heating. The dominant spatial pattern of the monsoon ISV is associated with a dipole structure in the north-south direction (see Goswami 2005) with a clear condition in central and north India and cloudy (rainy) condition over equatorial Indian Ocean during a break while the situation reverses during an active condition. Thus, during a break, aerosol concentration builds up in central and north India through local emissions and long range transports while the north Indian Ocean remains 

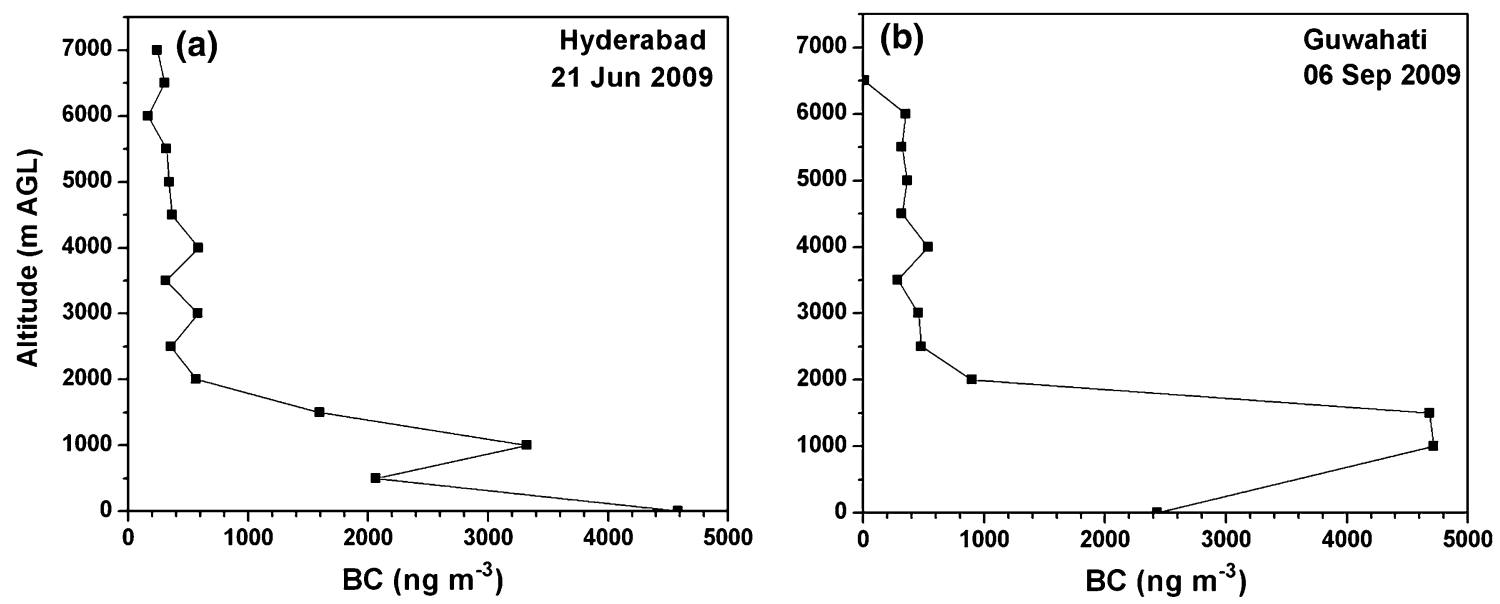

Fig. 1 Vertical profile of black carbon aerosol measured by an Aethalometer during CAIPEEX Phase-I. Significant loading of BC between 1 and $3 \mathrm{~km}$ is seen over the stations a Hyderabad in central India on June 21, 2009 and b Guwahati in north-east India on 6 September 2009

relatively pristine. As a large fraction of these aerosols is of absorbing type (Menon 2004; Chakraborty et al. 2004; Bollasina et al. 2008), they would cool the surface but warm the atmospheric layer between 1 and $3 \mathrm{~km}$. Such warming of the lower atmosphere over central and north India and lack of it over the north Indian Ocean would lead to a north-south temperature gradient at this level and convergence of moisture to central and north India. Such moisture convergence could overcome the stabilization effect due to surface cooling and lead to organization of convection and transition to an active condition. By using several data sets, here we demonstrate that the transition of several strong and relatively long breaks to active conditions is consistent with this hypothesis. It may be noted that the breaks have to be long enough (at least more than a week) and circulation conducive for the build-up of aerosols to be adequate for the aerosol feedback to be effective. Also we do not expect a similar feedback for transitions from active to break conditions as during an active condition we do not expect the north south temperature gradient anomaly to reverse due to the fact that even though the precipitation anomaly has reversed, there is no local source over the ocean and hence there may not be significant build up of absorbing aerosols over the ocean.

When we are talking about large aerosol loadings during break conditions, we need also to consider the possible aerosol indirect effect namely, the Twomey effect, which under fixed liquid water content condition, could delay or inhibit initiation of rain. However, we do expect that the large-scale convergence of moisture triggered by meridional temperature gradient could break this constraint and overcome the indirect forcing of aerosols. The effectiveness of the moisture convergence in achieving this would depend on the amount of heating caused by the absorbing aerosols over the Indo Gangetic Plain (IGP) region lying in central India, which may vary from one break event to another. This process, therefore, may also contribute to event-to-event variability of the monsoon ISV.

The data sets and methodology used in this study are described in Sect. 2. Results from our analysis are documented in Sects. 3 and 4 and summarized in Sect. 5.

\section{Data and methodology}

In the present investigation, the modulation of intraseasonal oscillations (ISO) of the ISM by aerosols, during the period 2000-2009, is analyzed. For this purpose, we use the daily Aerosol Optical Depth (AOD) at $550 \mathrm{~nm}$ (MOD08_D3.005 Version 5, Level-3 data) and total column Precipitable Water Content (PWC) provided by the MODerate resolution Imaging Spectroradiometer (MODIS) onboard the Terra Satellite, available at a resolution of $1^{\circ} \times 1^{\circ}$ from the URL http://gdata1.sci.gsfc.nasa.gov/ daac-bin/G3/gui.cgi?instance_id=MODIS_DAILY_L3.

In addition, the following observational data sets have been used: daily OLR (Outgoing Longwave Radiation) measured from Advanced Very High Resolution Radiometer onboard National Oceanic and Atmospheric Administration polar orbiting spacecraft (Gruber and Kruger 1984) available from http://www.cdc.noaa.gov/ of Climate Diagnostics Center, Boulder at a resolution of $2.5^{\circ} \times 2.5^{\circ}$ resolution; daily circulation data from National Center for Environmental Prediction/National Center for Atmospheric Research (NCEP/NCAR) Reanalysis (see Kalnay et al. 1996, available from http://www.cdc.noaa.gov/); daily $1^{\circ} \times 1^{\circ}$ gridded precipitation data from Global Precipitation Climatology Project (GPCP; Huffman et al. 2001; http://ftp.ncdc.noaa.gov/pub/data/gpcp/1dd-v1.1); daily temperature, wind and specific humidity data set from 
ECMWF Re-analysis (ERA-Interim Project) available at a horizontal resolution of $1.5^{\circ} \times 1^{\circ}$ from the website http://data-portal.ecmwf.int/data/d/interim_daily/; daily Aerosol Index (AI) and Total Column amount Ozone (TCO) from the Total Ozone Mapping Spectrometer (TOMS; Hsu et al. 1999; for the period 2000-2004; URL http://gdata1.sci.gsfc.nasa.gov/daac-bin/G3/gui.cgi?instance_ $\mathrm{id}=$ toms) and from Ozone Monitoring Instrument (OMI; for 2005-2009; URL http://gdata1.sci.gsfc.nasa.gov/daacbin/G3/gui.cgi?instance_id=omi).

The first part of our analysis aims at identifying long break spells followed by active spells during the period 2000-2009. Since high OLR values represent suppressed convection and low OLR values represent increased convection and the break (active) spells constitute consecutive days having high (low) OLR values, we have used standardized OLR anomalies for the identification procedure, following Joseph et al. (2009). Breaks (actives) are identified when the standardized OLR anomaly averaged over the Central Indian $(\mathrm{CI})$ region $\left(73^{\circ}-82^{\circ} \mathrm{E} ; 18^{\circ}-28^{\circ} \mathrm{N}\right)$ is more (less) than $0.9(-0.9)$ for consecutive 4 days and the average standardized anomaly over the region during the period exceeds (goes below) $1.0(-1.0)$. We noted that during this period, there were six relatively long breaks (more than 7 days) that were followed by an active condition (Fig. 2). We call them BFA cases. We construct composites of various dynamical and thermodynamical fields together with aerosol properties during breaks to understand the role of aerosol in transition from break to active conditions. It is also found that there are three long breaks during this period that were not followed by an active condition, the BNFA cases (Fig. 2). Composites of AOD and AI were constructed for BNFA cases based on these three cases. While aerosol data is not available prior to 2000, wind and OLR data is available from 1975 onwards. Four more cases of long breaks that were not followed by an active spell were found between 1975 and 2000. Therefore, composites of winds and OLR for the BNFA cases were based on the seven events. While here we use an OLR index to identify active and break spells of Indian monsoon, they could also be identified by using a variety of other indices, such as a rainfall averaged over the monsoon trough zone (Rajeevan et al. 2010) and a zonal wind index over Bay of Bengal south of the monsoon trough (Goswami and Ajaya Mohan 2001). It is found that breaks identified by the OLR index used here follow very closely those identified by the monsoon trough zone precipitation index (Rajeevan et al. 2010).

A Radiative Transfer Model SBDART (Santa Barbara Discrete ordinate Atmospheric Radiative Transfer; Ricchiazzi et al. 1998) is used to simulate the surface downward and top-of-the-atmosphere (TOA) shortwave
(SW) flux and the heating rate (HR) for aerosol laden and aerosol-free atmospheres, during the break spells. Daily mean aerosol parameters, TCO and PWC were used to simulate clear sky radiative fluxes using the SBDART model for all the days. Other input parameters used by the program are the solar radiation, the solar geometry, the surface reflective properties and a model atmosphere. Aerosol Asymmetry Parameter (ASP), Single Scattering Albedo (SSA) obtained from the Global Aerosol Data Set (GADS; d'Almedia et al. 1991; Koepke et al. 1997; source-http://www.lrz-muenchen.de/ uh234an/www/ radaer/gads.html) and a tropical model atmosphere (McClatchey et al. 1972) have been used in this discrete ordinate model. Since the presence of clouds can pose a major concern for the estimation of aerosol-induced heating rate, the same has been estimated by considering the vertical distribution of cloud properties. Estimated SW radiative fluxes and HR at one-hourly intervals are averaged for the daily mean values. Fluxes at the surface and TOA were estimated under aerosol free atmospheres.

\section{Results and discussions}

As discussed earlier, a variety of physical processes spanning over diverse temporal and spatial scales interact nonlinearly to modulate the ISOs. The role of aerosols, particularly of absorbing nature, over the Indian monsoon region in modulating the ISOs is unraveled in this particular study.

While aerosols like sulfates, nitrates and sea salt primarily scatter the solar radiation, absorbing aerosols such as black carbon, smoke and mineral dust alter the spatial gradient in the atmospheric solar heating, and this alteration has been shown to perturb the spatial distribution of monsoonal rainfall in East and South Asia, with more rains in some regions and less in others (Ramanathan et al. 2005). Human-made absorbing aerosols in populous industrial regions can alter the net radiant energy available to earth-atmosphere system and modify the atmospheric circulation and contribute to regional climate change (Menon et al. 2002). Yet the impact of aerosols on monsoon ISV remains largely unknown due to their heterogeneous physico-chemical characteristics and large spatio-temporal variability (Bhawar and Devara 2010).

As our objective is to understand the transitions from break to active spells, first we examine the anomalies of aerosols, circulation and convection during BFA cases in this section. The anomalies for the BNFA cases will be examined in the next section to bring out the role of aerosols in these transitions. 
Fig. 2 a Standardized OLR anomalies for the period 2000-2009. Long break cycles (thick black solid circles) followed by active spells (thin black circles) together with followed by active episodes those breaks immediately not (thick red circles)

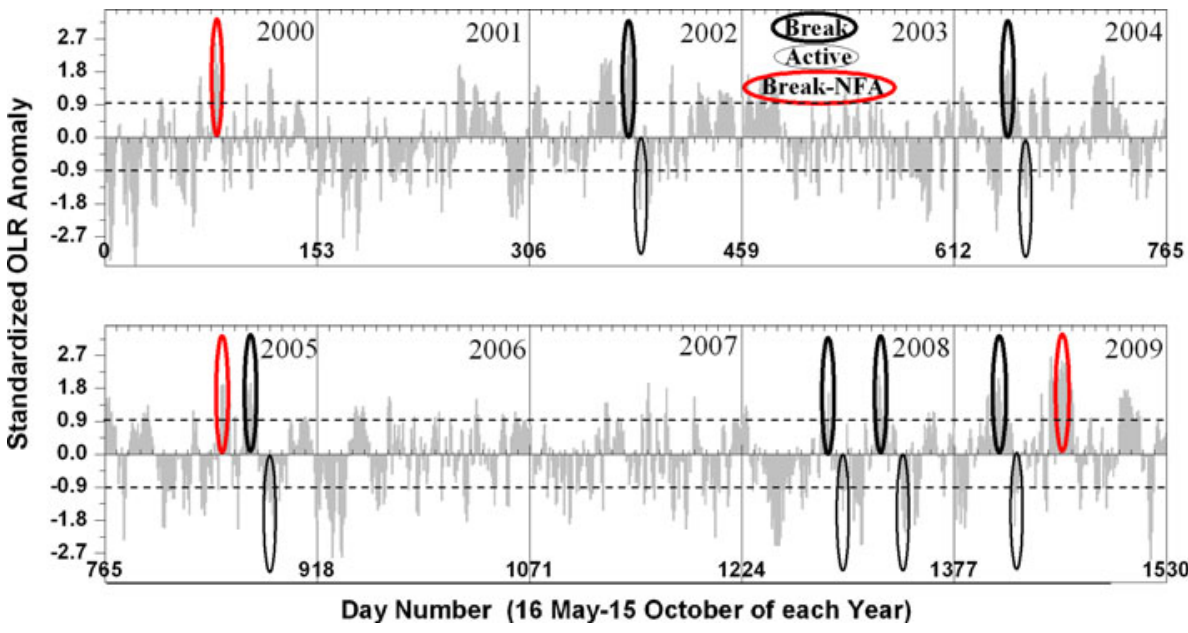

3.1 Composite circulation and OLR anomalies during BFA cases

Typical structure of anomalies of winds at lower level and that of OLR during active and break spells are shown in Fig. 3a-d. These figures have been produced from composites of $850 \mathrm{hPa}$ wind and OLR anomalies during corresponding spells. The shaded portions in Fig. 3a, b represent the strength of the horizontal wind anomalies. A notable characteristic of the circulation is that it gets intensified as it crosses the equator and it flows as westerly anomaly over the Indian subcontinent during active condition. The pattern of this anomaly is cyclonic in nature over the continent especially over the monsoon trough region. During break monsoon time, the anomalies undergo a reversal making it anticyclonic anomalies over the continent. This is a period when anomalous subsidence occurs over the continental region and prevents convection producing large-scale reduction in precipitation. As is established, the composite OLR anomalies (Fig. 3c, d) also show contrasting spatial structures during break and active cycles with a characteristic meridional dipole pattern. In the following sections we will try to examine the spatial distribution of aerosol parameters, their source regions and radiative characteristics.

\subsection{Aerosol loading and its anomalies during BFA cases}

The spatial distribution of composite of actual AOD during both break and active spells has been plotted in Fig. 4a, b, respectively. The most striking feature of Fig. $4 \mathrm{a}$ is that aerosol loading is the highest at the IGP and adjoining areas of eastern Pakistan and Himalayan foothills, and is gradually decreasing southwards over both continental and oceanic regions during break. The IGP region is located in the northern part of India and surrounded by the unique topography with the Himalayas to the north and hills to the south. The entire IGP is one of the highly polluted regions in India. Because of growing population and economic growth, air pollution is a serious environmental problem in this region. The region has witnessed impressive growth rates in agricultural productivity since the dawn of the industrial era, accompanied by significant land-use modification and changes. Convincingly, recent measurements indicate that the IGP is also one of the major source regions for various natural and anthropogenic aerosols (Tare et al. 2006; Tripathi et al. 2006; Rengarajan et al. 2007). The uneven topography rising from sea level to about $6 \mathrm{~km}$ (Jai Devi et al. 2010) act both as preferred centres for local convection and barriers to the free flow of air at lower levels. As has been shown in Fig. 3a, there are westerlies over the IGP region; southerlies over the north Arabian Sea and easterlies in the south Arabian Sea during break. Due to the anticyclonic nature of the circulation anomalies over the north-central India, there is large-scale subsidence and this may enhance the confinement of aerosols to the lower atmosphere. Thus there exists a great range of spatial asymmetry of AOD across the country. A maximum value of AOD (of the order of 1.0 or more; Ravi Kiran et al. 2009) is observed over the IGP region. Furthermore it is interesting to note that the location of the maximum loading of aerosols during break monsoon condition is located north of but parallel to the climatological position of the monsoon trough. During active conditions, the aerosol loading (Fig. 4b) is significantly reduced everywhere over central India and northern Arabian sea compared to break conditions (Fig. 4a). The main contrast, however, is over the IGP region where it reduces from a very high value during breaks to very low value during active spells.

In order to examine whether this loading is persistent throughout the monsoon period, the AOD anomaly was estimated. Figure $4 c, d$ depict the AOD anomaly during break and active conditions respectively. The two 
(a)

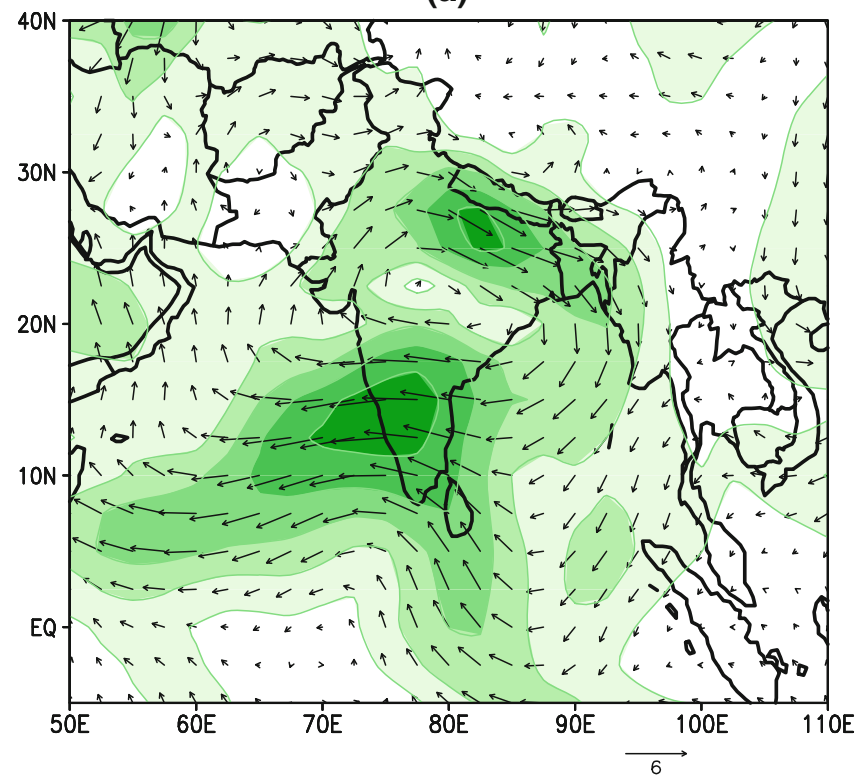

(b)

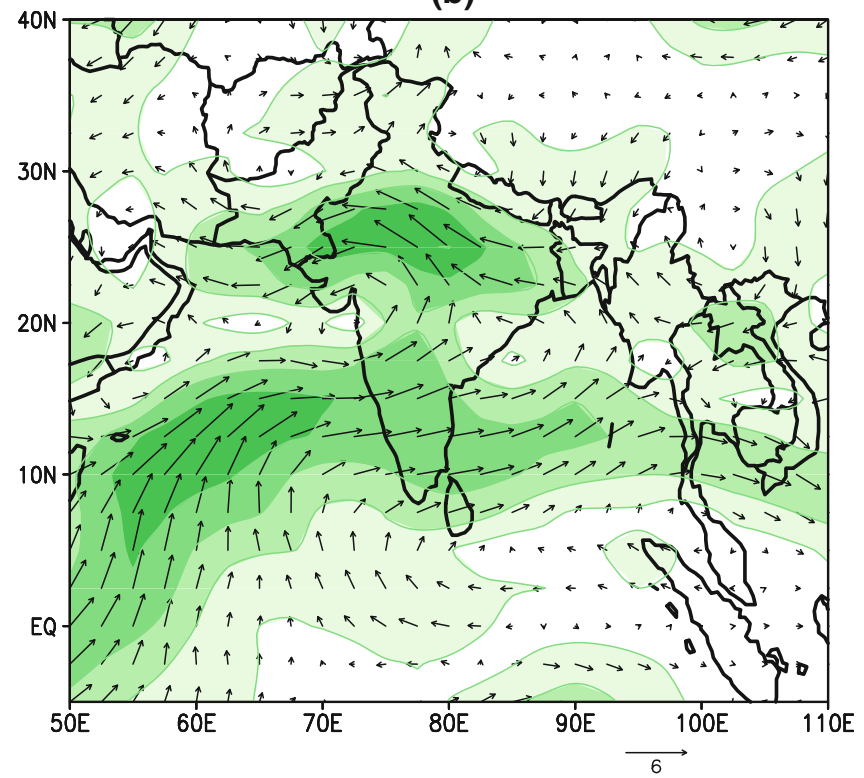

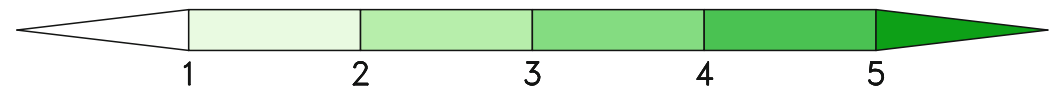

(c)

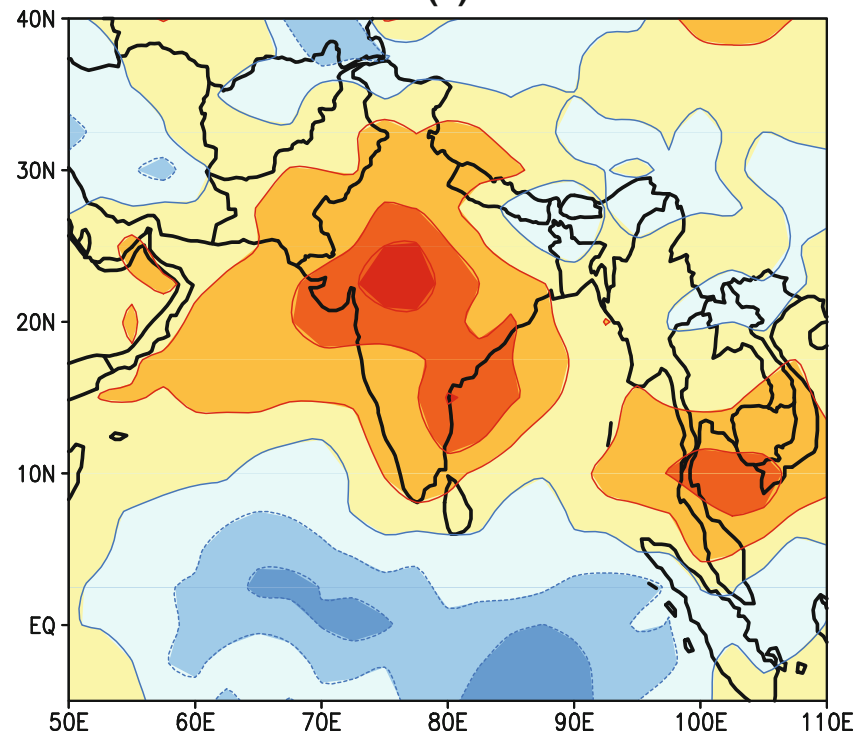

(d)

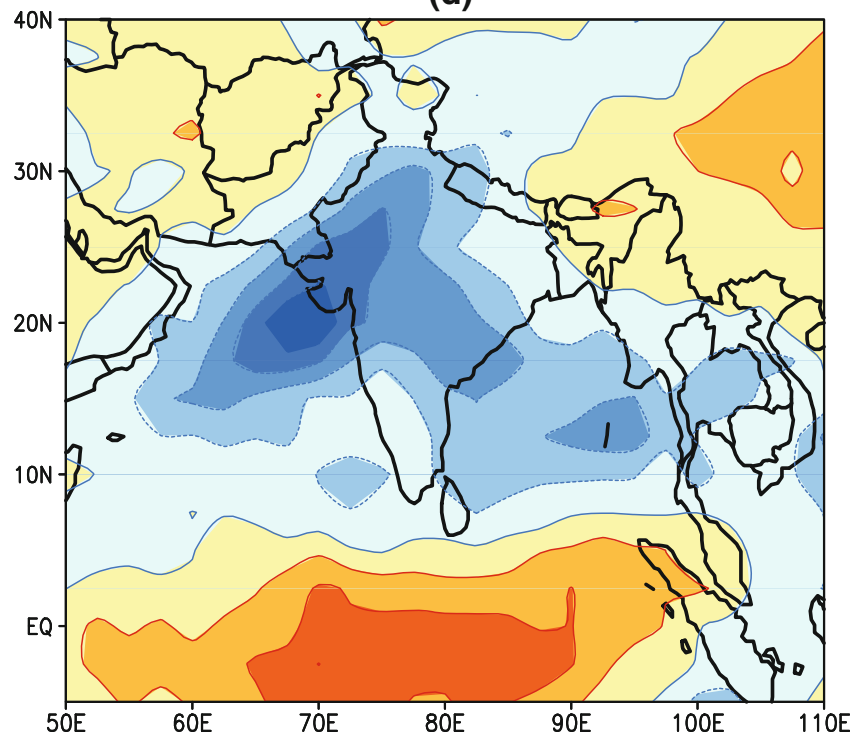

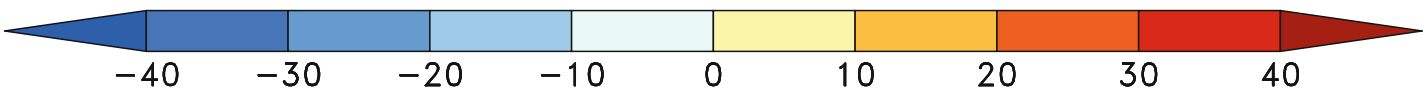

Fig. 3 Composite of circulation anomalies in $\mathrm{m} \mathrm{s}^{-1}$ during BFA cases: a breaks $\mathbf{b}$ actives. $\mathbf{c}$ and $\mathbf{d}$ are same as a and $\mathbf{b}$ respectively, but for OLR anomalies in $\mathrm{W} \mathrm{m}^{-2}$

rectangular boxes, one of which marks the continental central India $\left(75^{\circ}-92^{\circ} \mathrm{E}, 22^{\circ}-28^{\circ} \mathrm{N}\right.$; hereafter referred to as Land) and the other marking the equatorial Indian Ocean region $\left(50^{\circ}-95^{\circ} \mathrm{E}, 5^{\circ} \mathrm{S}-7^{\circ} \mathrm{N}\right.$; henceforth referred to as Ocean) do represent a dipole-like pattern of AOD anomaly during active and break situations, similar to a case study reported recently by Rahul et al. (2009). It is again worthwhile to note that the sign of AOD anomaly over both of these two locations change alternatively from break to active phase and vice versa. During breaks, the anomaly over certain parts of land exceeds +0.3 and that over oceanic region is negative with values ranging between 0.0 and -0.1 . Similarly in the case of active, land region is characterized by anomalously negative AOD reaching 
(a)

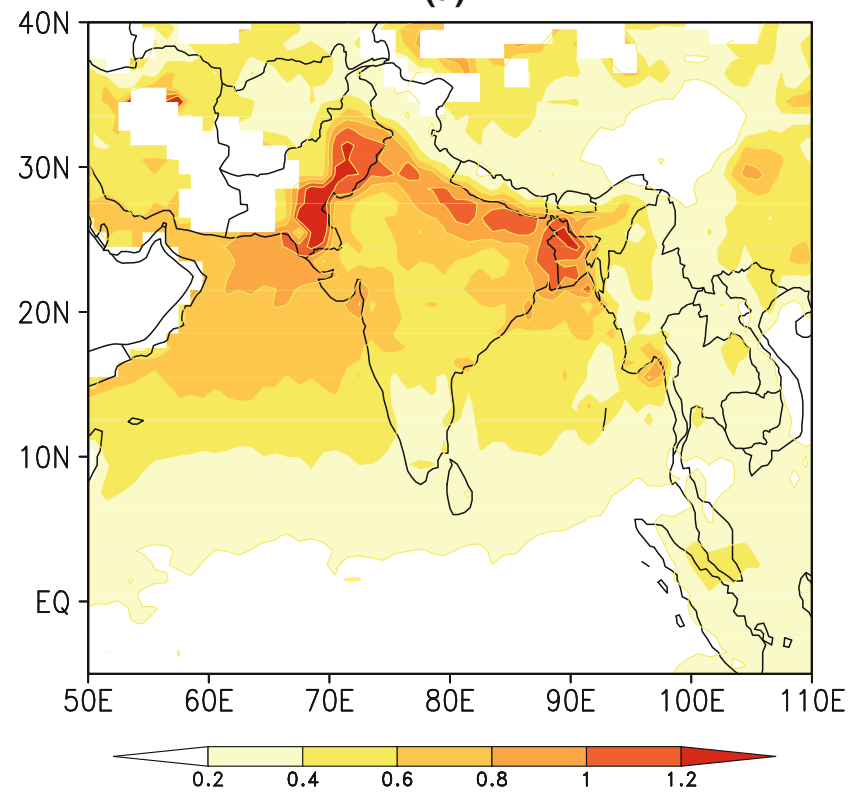

(c)

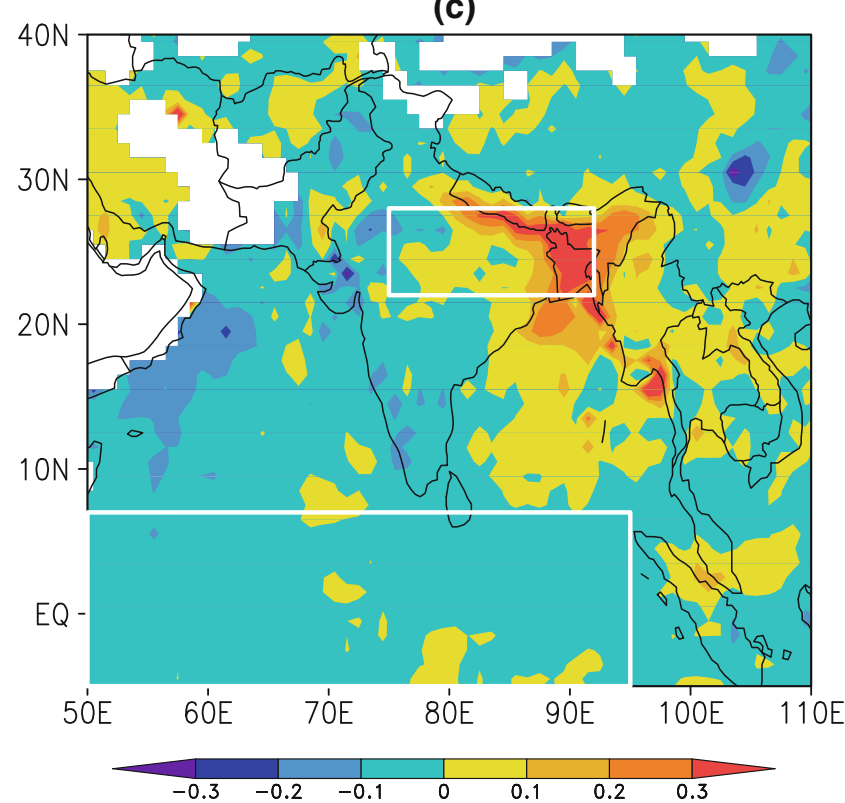

(b)

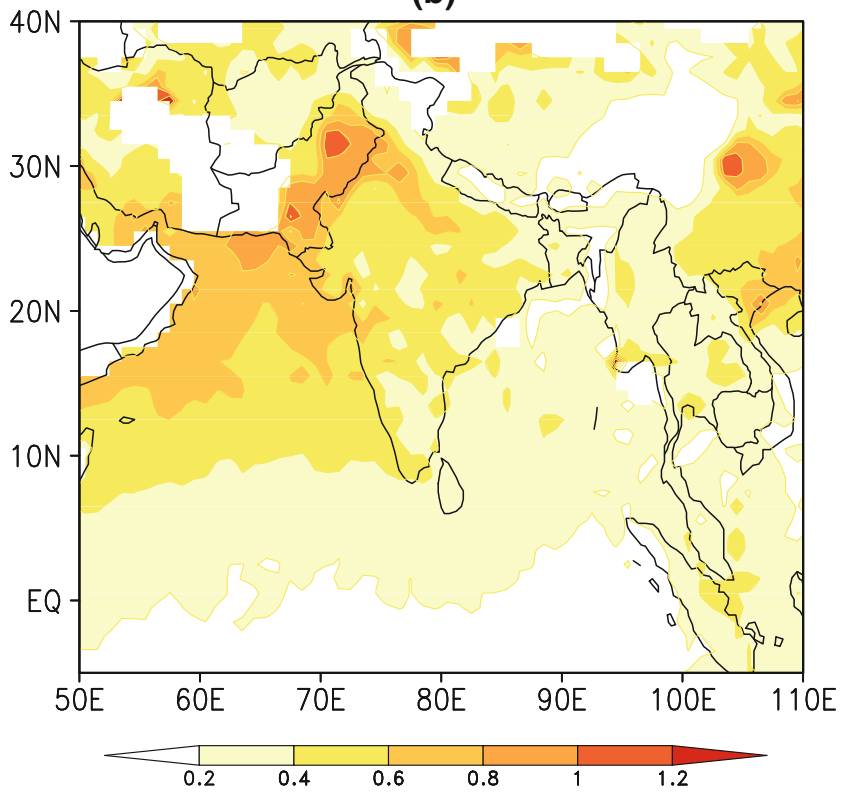

(d)

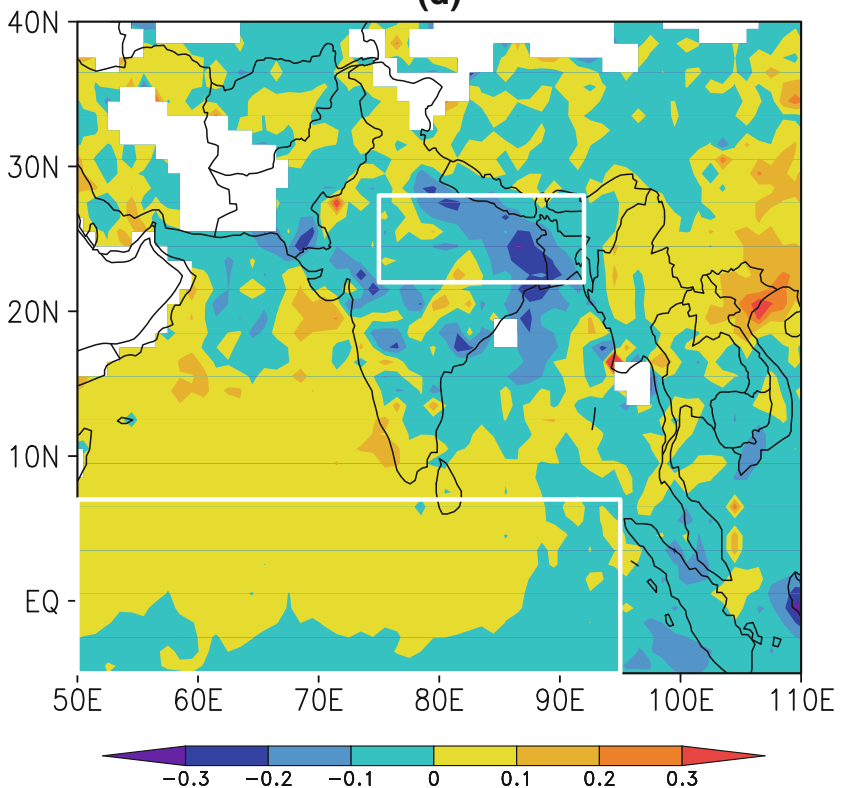

Fig. 4 Composite of actual AOD at $550 \mathrm{~nm}$ during BFA cases: a breaks and $\mathbf{b}$ actives. Composite AOD anomaly at $550 \mathrm{~nm}$ during $\mathbf{c}$ breaks and d actives

-0.3 whereas the oceanic region is differentiated by relatively positive anomalies. The negative anomaly of aerosol concentration over land region during active condition is mostly due to removal mechanisms such as rainout and washout. The difference between the AOD anomalies between the CI land and the equatorial Indian Ocean is found to be statistically significant at $95 \%$ CI level both during break and active conditions. This aspect of anomalous loading of aerosols has profound implications on dynamical response and precipitation amount, as has been demonstrated in the next sections.

\subsubsection{Type of aerosols}

While the contrast of aerosol loadings during active and break spells is remarkable, their radiative property depends crucially on the type of aerosols (Bhawar and Devara 2010). Here we utilize the Aerosol Index data to distinguish 
absorbing aerosols from scattering ones. AI is a measure of how much the wavelength dependence of backscattered UV radiation from an atmosphere containing aerosols differs from that of a pure molecular atmosphere. Quantitatively, $\mathrm{AI}$ is defined as $\mathrm{AI}=-100\left[\log _{10}\left(\frac{I_{331}}{I_{360}}\right)_{\text {meas }}\right.$ $\left.-\log _{10}\left(\frac{I_{331}}{I_{360}}\right)_{\text {calc }}\right]$, where the $I_{\text {meas }}$ is the measured backscatter radiance and $I_{\text {calc }}$ is the calculated radiance for a pure Rayleigh atmosphere. Mostly, the AI is positive for absorbing aerosols and negative for non-absorbing aerosols. Absorbing aerosols (desert dust, smoke, BC, volcanic ash, mineral dust coated with black carbon etc.) decrease the spectral contrast yielding positive AI values. The magnitude of AI depends mainly on aerosol properties like total optical depth, single scattering albedo, particle size distribution etc. (for details see the URL: http://macuv. gsfc.nasa.gov/OMIAerosol.md).

The composite AI during BFA breaks is portrayed in Fig. 5a. The greater magnitude of positive AI over the north and north-western part of India and northern-most Arabian Sea clearly shows that these regions are dominated by the presence of mostly absorbing type of aerosols. Observations show that the IGP experiences a very persistent and heavy aerosol burden (e.g., Ramanathan and Ramana 2005) and the composition in large part made up of absorbing aerosols (single-scattering albedo as low as 0.85, Ramanathan et al. 2001). The remaining parts of the oceanic and continental regions are covered by lessabsorbing or scattering types of aerosols. The features seen over the IGP during breaks are considerably changed during active conditions as depicted by Fig. 5b. The magnitude of AI has come down significantly over the continental region, probably due to the removal mechanisms associated with active rainfall and change in largescale flow pattern, but the oceanic region remain largely unchanged w.r.t. the break monsoon conditions. Anomalous absorbing aerosols during BFA breaks is represented by the difference in spatial distribution between the AIs during both the episodes (break minus active) and shown in Fig. 5c. The IGP region is characterized by a large and significant increase in absorbing type aerosols during breaks compared to active conditions. This AI anomaly over CI during BFA breaks is also found to be statistically significant at $95 \%$ confidence level.

\subsubsection{Source region of aerosols}

For a comprehensive understanding, it is likely to seek where the aerosols are originating from. A country like India is home to a variety of sources. The changes in the land use pattern, deforestation, increased traffic, industrial activities etc. contribute significantly to the atmospheric burden of these particles. This anthropogenic contribution is besides the existing natural production due to versatile processes. Carbonaceous aerosols are originated as result of biomass burning and fossil fuel consumption. Because $\mathrm{BC}$ aerosols can affect human health, agricultural yields, precipitation, temperature, and large-scale circulation through thermodynamical, radiative, and microphysical processes, their influence on regional and global climate can be quite significant, especially in areas where $\mathrm{BC}$ concentrations are high (Menon 2004).

The back trajectory analysis using the HYSPLIT (HYbrid Single-Particle Lagrangian Integrated Trajectory) model of NOAA-ARL (National Oceanic and Atmospheric Administration-Air Resources Laboratory) has given insight into the source region of long-range transported aerosols. The HYSPLIT model is a complete system for computing simple air parcel trajectories to complex dispersion and deposition simulations. Without the additional dispersion modules, HYSPLIT computes the advection of a single pollutant particle, or simply its trajectory. This program produces a plot of air parcel trajectories for userspecified end points and times using the HYSPLIT model which is available from the website: http://www.ready. noaa.gov/ready/open/traj.html.

The composite picture of back trajectories for three representative height levels ending at 500, 1,500 and $3,000 \mathrm{~m}$ above ground level at a representative receptor point $\left(80^{\circ} \mathrm{E}, 28^{\circ} \mathrm{N}\right)$ in the IGP during the break period is shown plotted in Fig. 5d. These altitude levels were chosen decisively to signify the atmospheric column which contributes the most towards the loading of aerosols (Charlson et al. 1992). The trajectories are for the previous 7 days w.r.t the ending time (00:00 UTC of each day) observing the fact that the residence time of aerosols is up to a week. A close inspection of Fig. 5d reveals that some portion of the air parcels are being transported from the eastern side of Sahara of Africa through the north-western parts of Arabian Sea and the adjoining desert region of Rajasthan. Another portion comes from the harsh desert regions of Afghanistan and eastern Pakistan. Additionally the trajectories pass through the highly populated and industrialized region of northern India thus getting modified by local environment. The red dotted lines represent trajectories at $500 \mathrm{~m}$, the green ones at $1,500 \mathrm{~m}$ and the blue lines portray those at 3,000 m. Furthermore, all the three trajectories are originating from the two different locations mentioned above. Thus it can be attributed that the anomalous aerosol loading is due to long range transport plus amplification by local input in a large-scale subsidence backdrop (Ravi Kiran et al. 2009). 
(a)

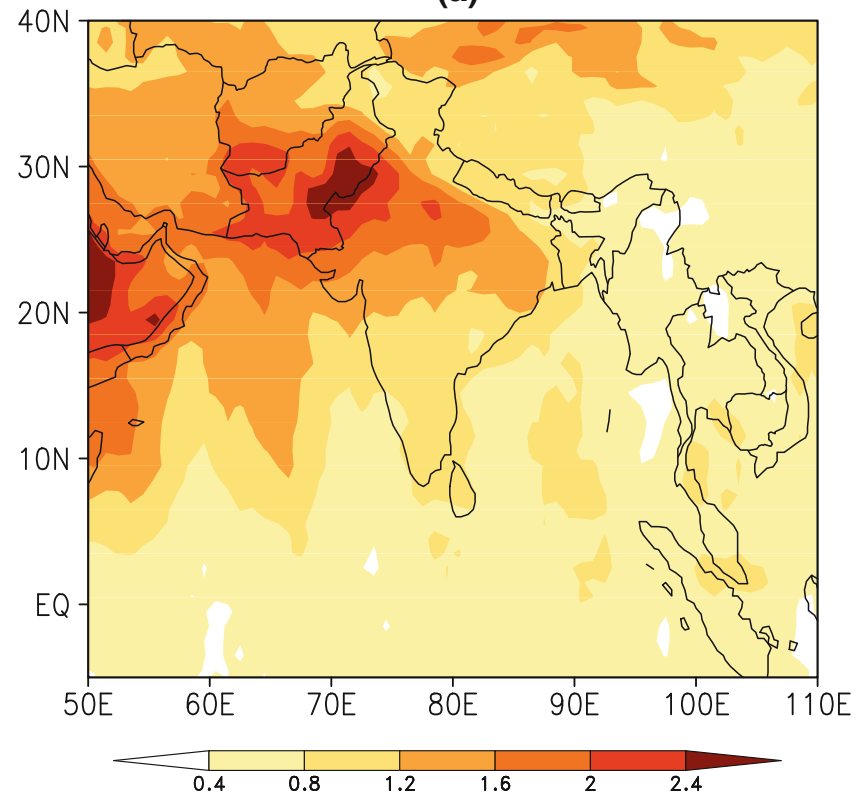

(c)

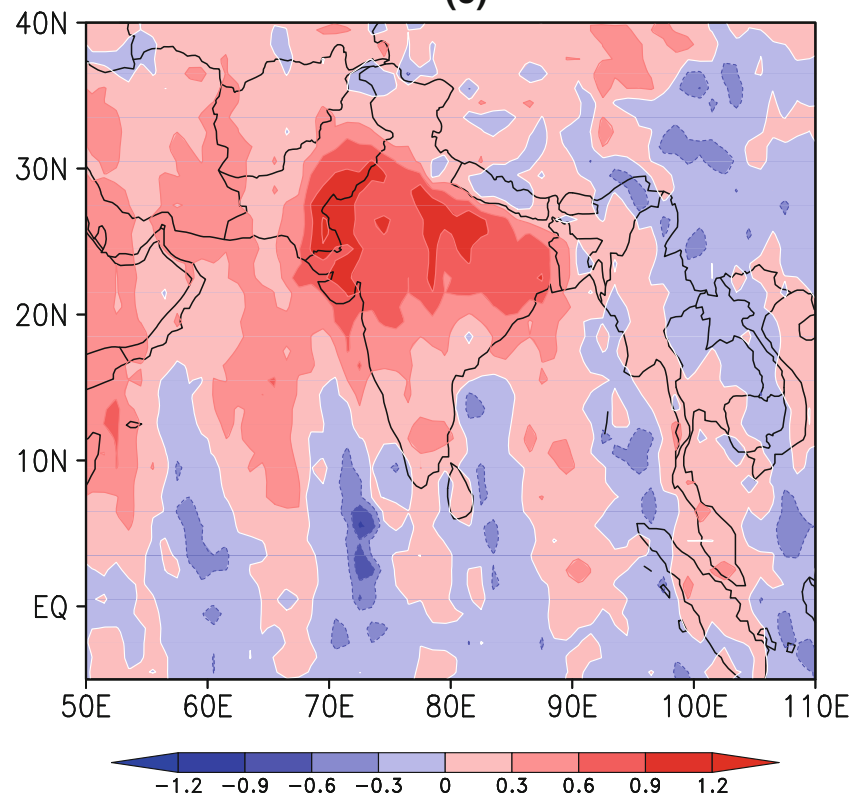

(b)

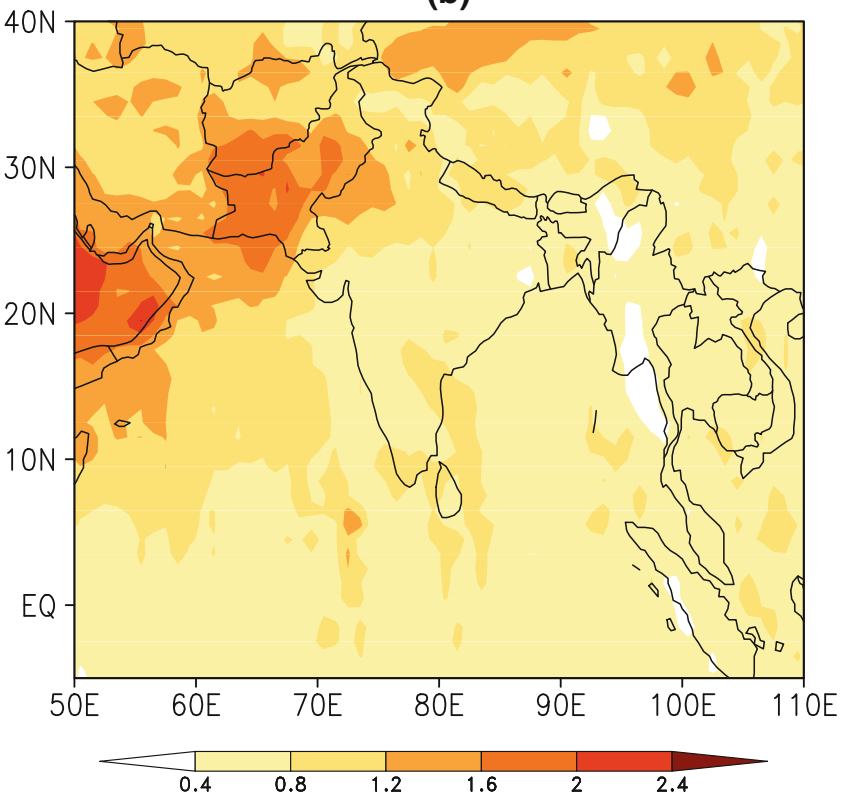

(d)

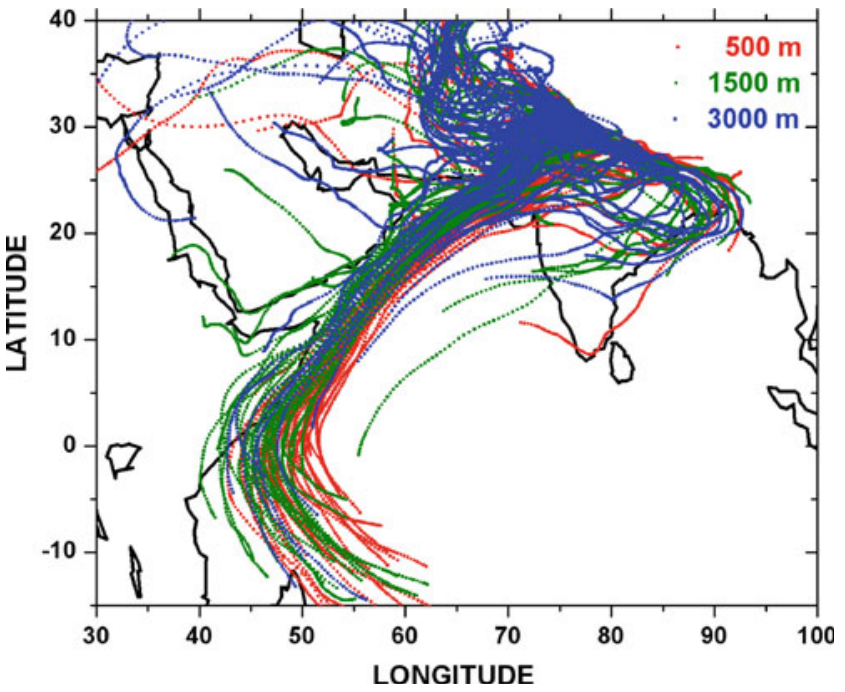

Fig. 5 Composite Aerosol Index during BFA cases: a breaks b actives $\mathbf{c}$ break minus active and d breaks composite of seven-day backtrajectories ending at 00:00 UTC at the receptor point $(80 \mathrm{E} ; 28 \mathrm{~N}$ ) over the Indo-Gangetic Plain for the altitudes 500, 1,500 and 3,000 $\mathrm{m}$

\subsection{Physical mechanism for transition}

This section tries to unravel the physical processes that lead to the resurgence of active rainfall episodes preceded by break events.

\subsubsection{Thermodynamical response}

The tropical monsoon environment is characterized by moist convective instability with relatively large amount of
Convective Available Potential Energy (CAPE). During break monsoon condition, due to large spatial variability of loading of absorbing aerosols in the atmosphere, a prominent but asymmetric forcing could be induced and could produce amplified heating over the central Indian land mass compared to the equatorial Indian Ocean to the south. In order to estimate the meridional gradient of temperature at low levels, two boxes, one over CI Land and the other over Indian Ocean (IO) are selected as shown in Fig. 4c, d. The box over Land is so selected that it encompasses the 
large aerosol anomalies. As the aerosol variability is rather weak over the ocean, a larger box is taken over the equatorial IO to represent the large scale temperature distribution. The composite anomaly of vertical temperature profiles (obtained from ERA-Interim Project) of the atmosphere over the Land during both the phases of ISOs differ substantially from those of Oceanic region (Fig. 6a). The difference between the anomaly of vertical temperature profiles over Land and Ocean $\left(\Delta T_{\text {anom }}=T_{\text {anom }}^{L}-\right.$ $T_{\text {anom }}^{O}$ ) during the break spells (red line) dictates that there is remarkable discrepancy in $\Delta T_{\text {anom }}$ in the lower troposphere extending up to about $800 \mathrm{hPa}$ level with maximum value of $\Delta T_{\text {anom }}(>1.7 \mathrm{~K})$ up to $925 \mathrm{hPa}$ level. At about $700 \mathrm{hPa}$, this difference seems to be negligible and then starts changing the sign. During active episodes, the situation is reverse (green line) with the difference being negative at the lower levels mainly because of the drop in temperature over the Land.

\subsubsection{Dynamical response}

Transition from a break spell to an active spell requires transition of a suppressed convective regime to an active organized convective regime. In this section, it is demonstrated that the large spatial gradient of atmospheric heating induced by absorbing aerosols during long breaks could lead to large-scale convergence of moisture flux and low-level uplift necessary for organization of convection. Further, the moisture flux would enhance the moist-static instability, thereby providing an environment conducive for the triggering of convection and transition to an active condition.

Since sustained deep convection requires mean lowlevel moisture convergence (Holton 2004), the transition of moisture congregating over the $\mathrm{CI}$ region at $925 \mathrm{hPa}$ is analyzed in conjunction with the time evolution of difference in mean temperature at the same pressure level over Land and Ocean (Fig. 6b). The red line in this figure indicates the temperature difference, blue line depicts the moisture convergence (MC) over $\mathrm{CI}$ and the green line represents the area averaged rainfall composite over CI. All the three parameters were smoothed by a three-point running mean. The $X$-axis of this figure is so chosen that the transition from break to active scenario is with respect to the mid-day of individual break spell. In other words, the days given on the time axis are relative to the day of midbreak. As has been shown, the temperature difference peaks to the maximum during the mid-break (zeroth day) and then gradually falls down towards the active epochs. Meanwhile, in response to this temperature difference, there is an outburst of moisture flux starting after the crest
Fig. 6 a Vertical profile showing difference of temperature anomaly (Land minus Ocean) in ${ }^{\circ} \mathrm{C}$ during the BFA breaks, actives and BNFA spells, b Composites of time evolution of temperature difference at $925 \mathrm{hPa}$ between Land and Ocean, moisture convergence at the same level and rainfall w.r.t. the mid-day of BFA break composite. c Same as b but moisture convergence replaced by moist static stability $\left(d \theta_{e} / d z\right)$ curve of BFA breaks composite
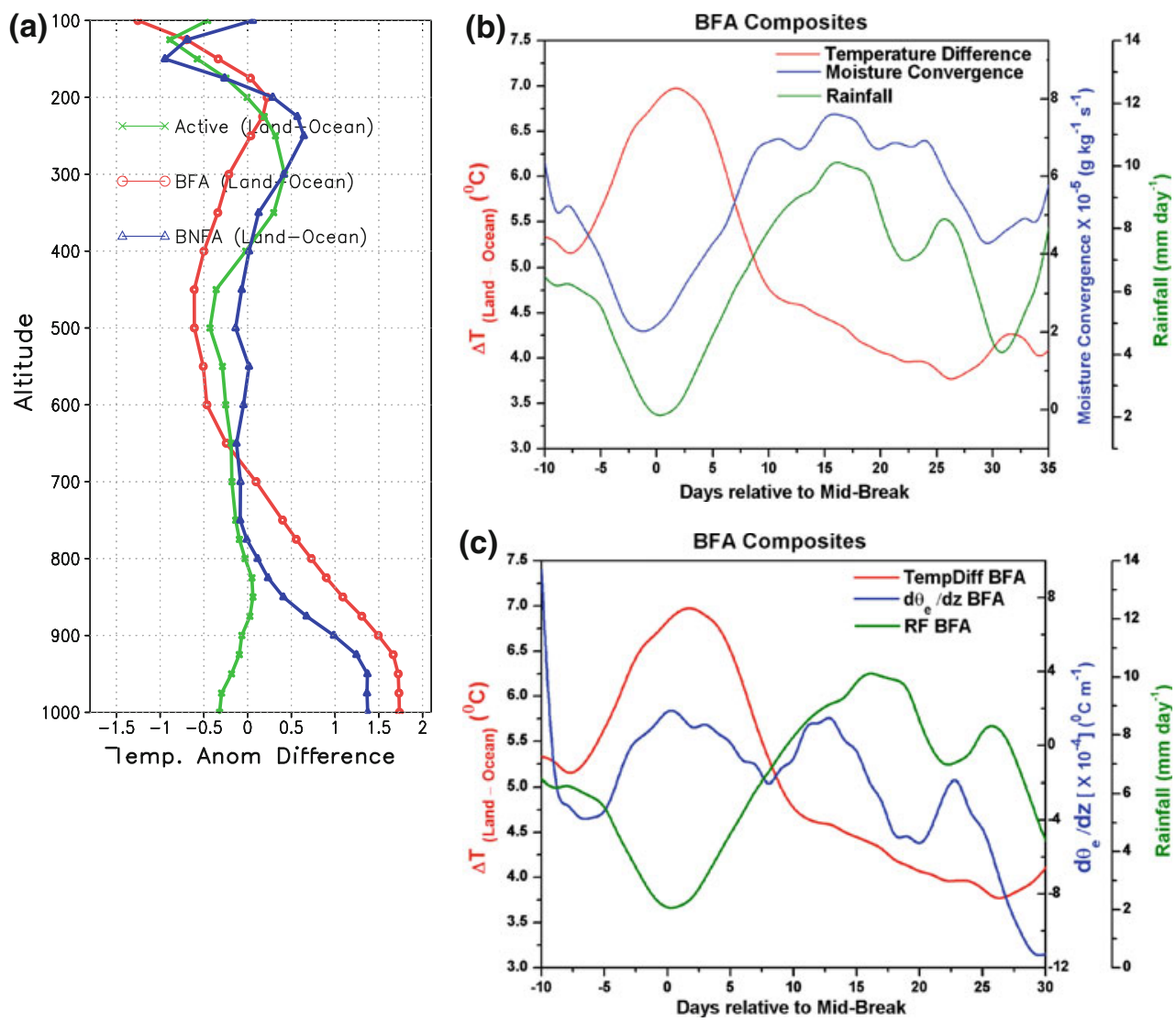
of break period and later peaking towards the mid-day of the active episodes. In a composite sense, the mid-day of active is separated from the mid-day of break by around 15 days. From the figure, it is clear that the maximum MC is during the mid-days of the active condition. Additionally it is shown that the MC is immediately followed by the rainfall with a lag of 1 day for most of the occasions and both of them follow similar pattern.

In order to examine the moist static stability of the atmosphere during the transition period, we have used the equivalent potential temperature $\left(\theta_{e}\right)$ at different altitudes. It is a quantity related to the stability of a column of air in the atmosphere. In stable conditions, $\theta_{e}$ increases with altitude and if it decreases with height $\left(d \theta_{e} / d z<0\right)$, convection can be triggered. The comparison of $\theta_{\mathrm{e}}$ of air parcels at different levels thus provides a measure of instability of the column of air. The equivalent potential temperatures at 1,000 and $900 \mathrm{hPa}$ have been used for the calculation of their vertical gradient because these two levels encompass the $925 \mathrm{hPa}$ level moisture convergence and would be helpful in examining the instability produced in that layer. This aspect is examined during the transition phase with the help of Fig. 6c. This figure is similar to Fig. $6 \mathrm{~b}$ except that the moisture convergence is replaced by the moist static stability curve (i.e., $d \theta_{e} / d z$ ) over the $\mathrm{CI}$ region represented by the blue line. It is significant to note that the stability curve goes up slightly after the mid-break, then starts falling down towards the end of the break phase and highly unstable condition prevails during active rainfall periods. This instability is produced as a result of the MC despite the local stable condition prevailing due to the surface cooling as a result of aerosol forcing. Thus, the sharp decrease of $d \theta_{e} / d z$ is an indication of favourable state of large-scale organized convection and in turn the revival of active phase subsequent to the break monsoon period. Additionally, there is a decrease of instability (relatively stable condition) after the rainfall maximum which could be attributed to the modification of atmospheric thermal structure due to cooling at the ground by high precipitation and warming at upper levels due to latent heat release. The aerosol induced meridional gradient of heating plays a catalytic role in initiating the organized convection and rainfall through increased moist instability. The deep heating associated with the rainfall strengthens the MC and maintains organized convection even against stabilization of the thermodynamic structure.

\section{Role of aerosols on the dynamical response}

While Fig. 6b, c makes a strong case for the dynamical process for transition from break to active spells, the quantitative contribution of the absorbing aerosols on producing the observed north-south temperature gradient has not been delineated. In spite of the fact that these breaks are associated with large quantity of absorbing aerosols (Fig. 5c), it is possible that horizontal advection of heat and adiabatic compression associated with the anomalous descending motion during such cases could contribute to the heating of the northern box and to the north-south temperature gradient. In order to isolate the role of the aerosols from the local dynamical and thermodynamical effects, we note that there are three long breaks that were not followed immediately by active conditions during this period, the BNFA cases (Sect. 2, Fig. 2). Composites of AOD and AI for the BFNA cases are shown in Fig. 7a, c. While the difference of AOD composites between BFA and BNFA cases show that there was only marginal increase in AOD over central India during BFA cases compared to BNFA cases (Fig. 7b), there were almost three times larger amount of absorbing type aerosols over CI region during BFA as compared to BNFA cases (Fig. 7d). Thus, even though the solar attenuation at surface may have been very similar in both cases of breaks, the aerosols during the breaks that were followed by active conditions were loaded with much larger number of absorbing type aerosols.

What was responsible in preferentially accumulating absorbing type aerosols during BFA cases and not in BNFA cases? In order to understand this, we examined the composite of $850 \mathrm{hPa}$ wind anomalies and OLR anomalies during BNFA cases (Fig. 8a, b) together with back-trajectories at three levels (Fig. 8c). It is interesting to note that the BNFA cases were characterized by a much larger convective activity in the eastern India, Myanmar and southwestern China (Fig. 8b) compared to the BFA cases (Fig. 3c) resulting in an outflow of air from central India to western Pacific (Fig. 8a). It is also noted that compared to the BFA cases (Fig. 5d), very little transport of desert air from the northwest to central India takes place during BNFA cases (Fig. 8c). Thus, much larger transport of desert dust aerosols and accumulation of the same due to associated closed circulation anomalies result in much larger concentration of absorbing type aerosol during BFA cases. On the other hand, much less transport of dust aerosol to central India and their outward transport from central India results in no significant accumulation of absorbing aerosols during BNFA cases.

To understand why the transition to active does not immediately follow the breaks during BNFA cases, we examine the north-south gradient of temperature between the north box over $\mathrm{CI}$ and the south box over the equatorial IO, together with convergence of moisture at low level and compare with those during BFA cases (Fig. 9a). It is noted that the north-south gradient of temperature $(\Delta \mathrm{T})$ larger than $6^{\circ} \mathrm{C}$ is sustained for more than 10 days during BFA while such temperature gradient is not reached even for 
(a)

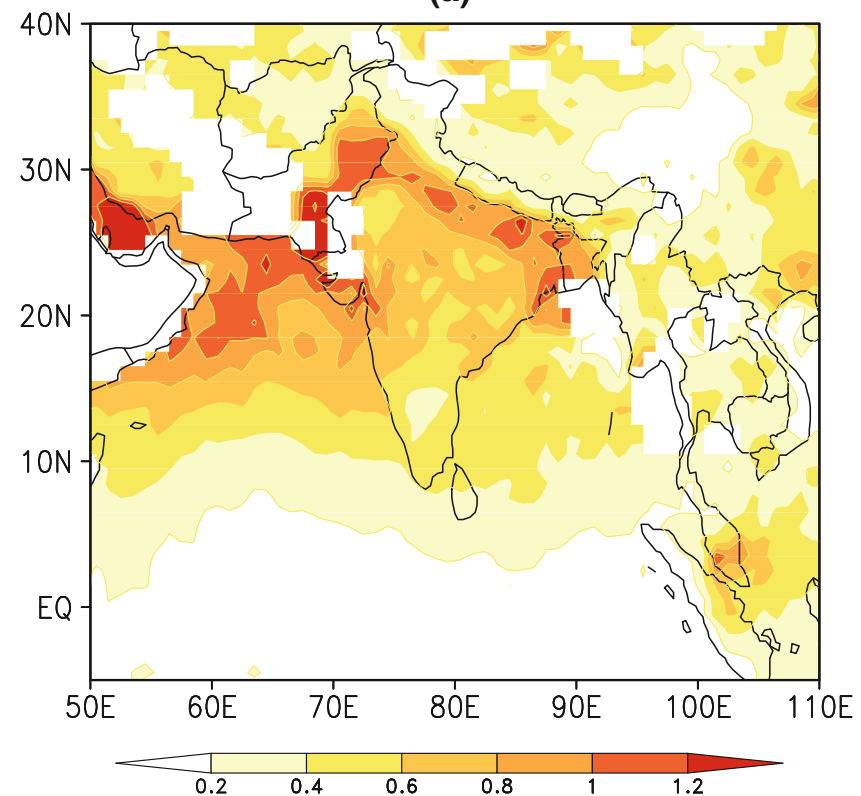

(c)

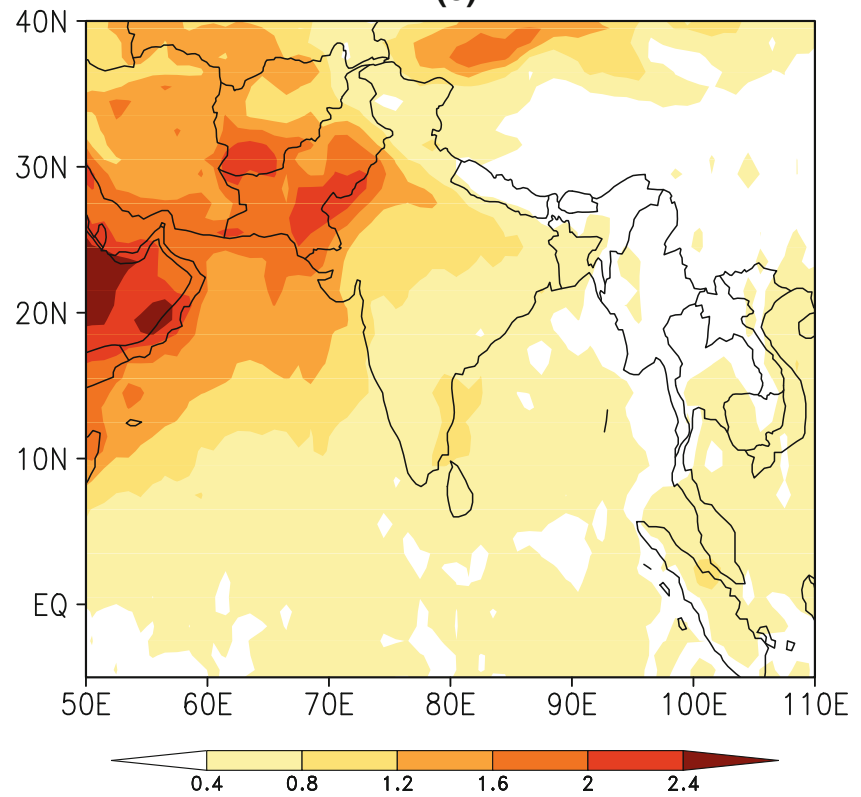

(b)

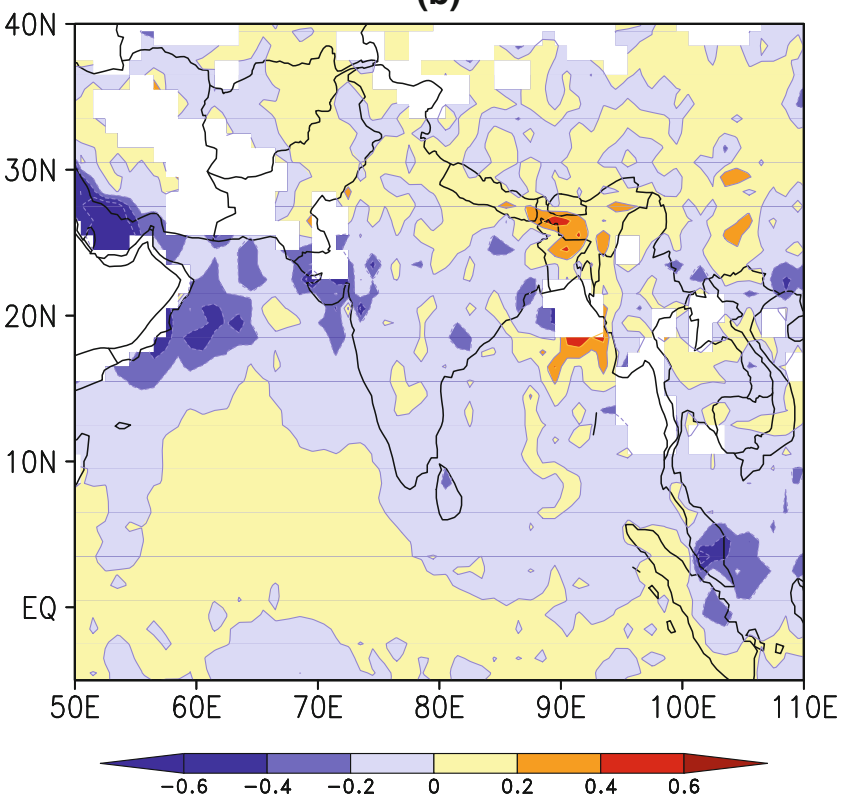

(d)

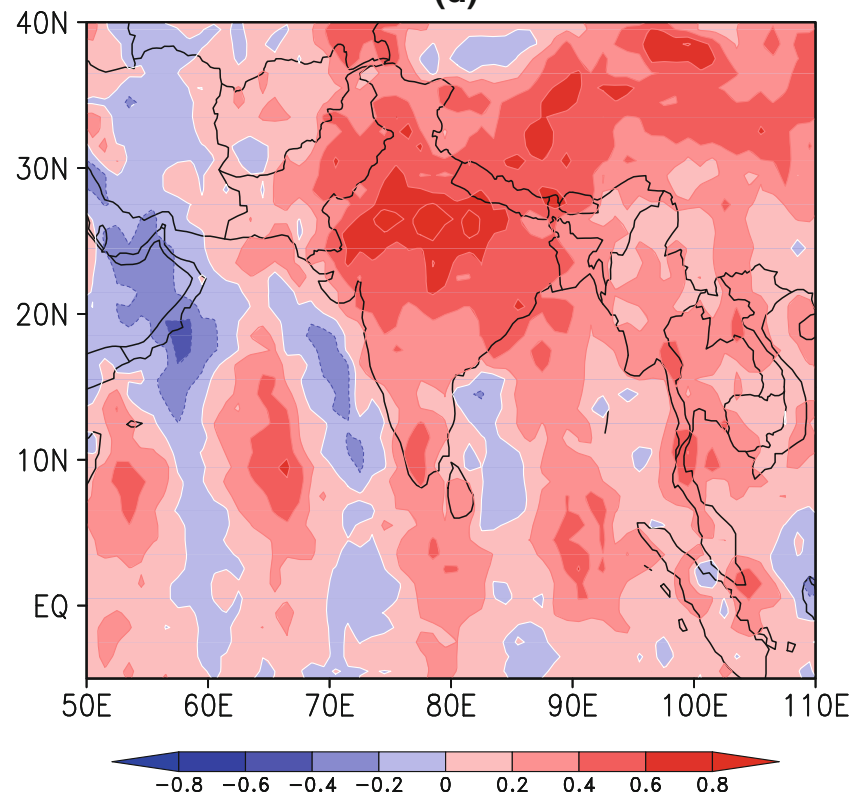

Fig. 7 Composite of actual AOD at $550 \mathrm{~nm}$ and Aerosol Index during BNFA and their difference with corresponding BFA break cases. a AOD (BNFA) b AOD (BFA minus BNFA) $\mathbf{c}$ AI (BNFA) and d AI (BFA minus BNFA)

1 day during BNFA cases. As a result of weaker $\Delta \mathrm{T}$ that does not sustain, moisture convergence is not only weak during BNFA cases, but also collapses immediately after reaching maximum. As a result, the rainfall increase following the BNFA cases could not be sustained and a sustained active condition does not develop. The vertical profile of difference in temperature anomalies over the north-box and south box during BNFA also shows that the temperature anomaly was weaker than the corresponding BFA case (blue line in Fig. 6a).
What is the relative role of heating over the continental box compared to the oceanic box in maintaining the $\Delta T$ ? To gain insight on this issue, lag composites of temperature averaged over the continental and the oceanic boxes are constructed for the BFA cases as well as the BNFA cases (Fig. 9b). Over the oceanic box, the temperature is nearly same during BFA and BNFA cases and has little variability during or after the break. Over the continental CI region, the temperature increases by $2.5^{\circ} \mathrm{C}$ during breaks compared to active periods and during BFA cases, it is about $1.5^{\circ} \mathrm{C}$ 
(a)

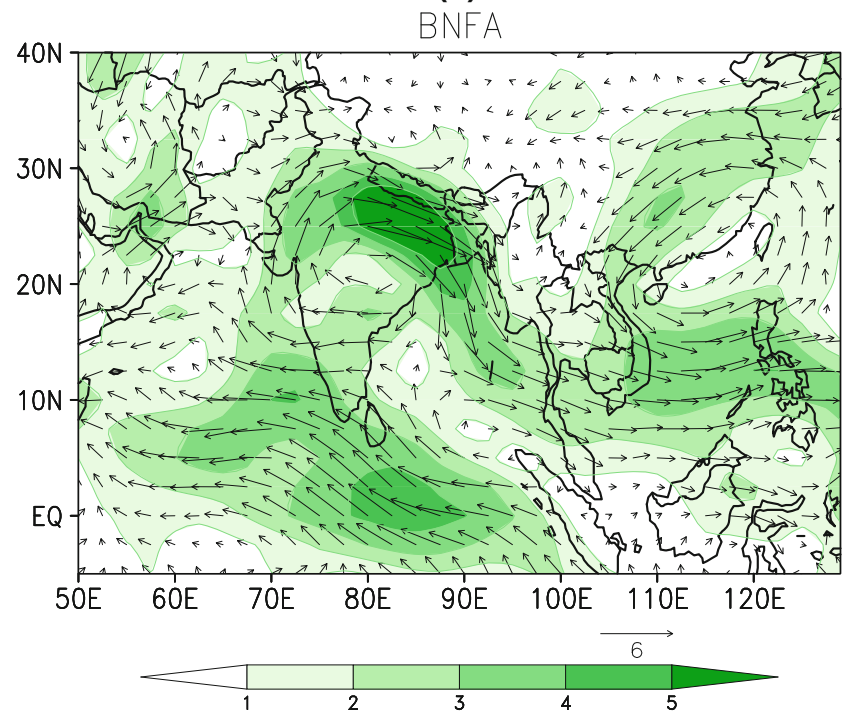

(b)

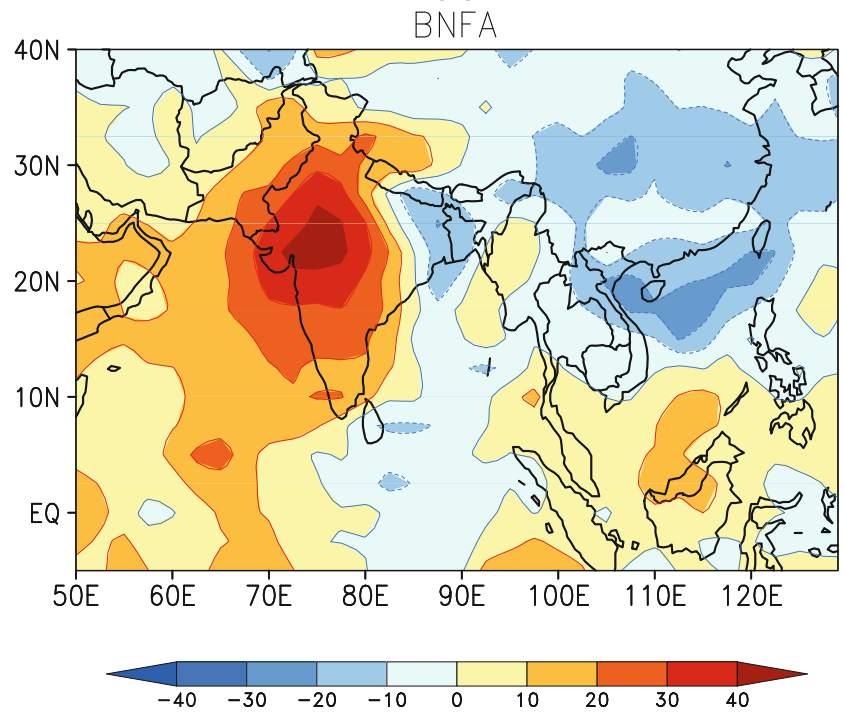

(c)

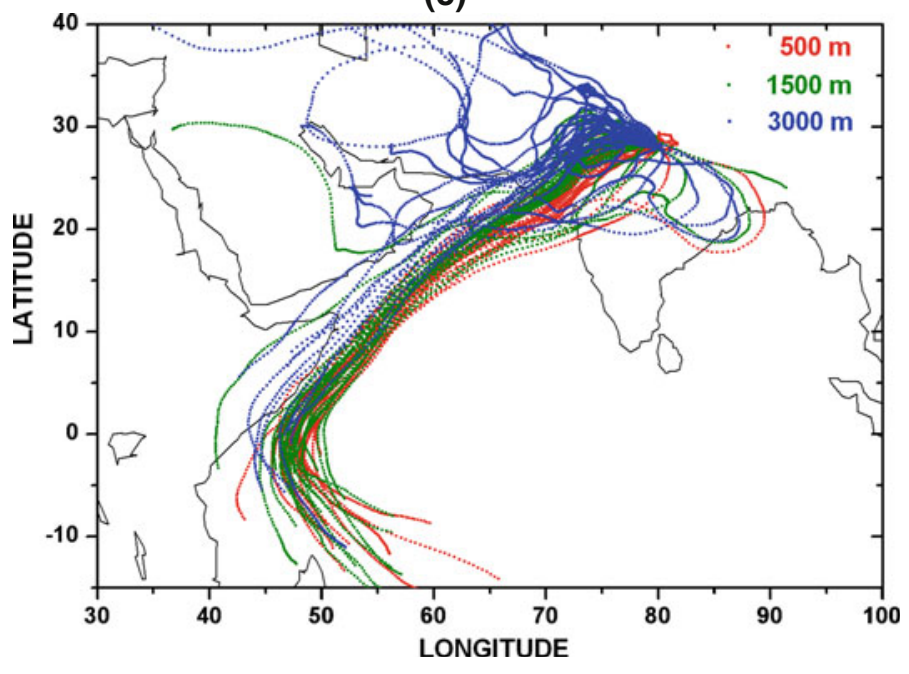

Fig. 8 Composite anomalies of $\mathbf{a} 850 \mathrm{hPa}$ wind in $\mathrm{m} \mathrm{s}^{-1}$ and $\mathbf{b}$ OLR in $\mathrm{W} \mathrm{m} \mathrm{m}^{-2}$ during BNFA cases. $\mathbf{c}$ Back-trajectories ending at 00:00 UTC at the receptor point $(80 \mathrm{E} ; 28 \mathrm{~N})$ at three height levels during BNFA

larger than during BNFA cases. The $\Delta T$ in Fig. 9a almost entirely comes from the CI box. Collocation of the anomalous absorbing aerosols with the warmer CI box, which drives the $\Delta \mathrm{T}$ and in turn drives the transition to active phases, strongly indicates the seminal role played by them in the transition process.

\subsection{Aerosol radiative forcing and heating rate of the atmosphere}

Direct Aerosol Radiative Forcing (ARF) is defined as the difference in net fluxes at the surface (SRF) or at the TOA, with and without aerosols. Such effects are produced by the optical, chemical and microphysical properties of the aerosols, nature of the underlying surface, cloudiness etc.
(Babu et al. 2002; Pandithurai et al. 2004). The ARF is given by the expression:

$(\mathrm{ARF})_{\mathrm{SRF}, \mathrm{TOA}}=\left[F_{A}-F_{N A}\right]_{\mathrm{SRF}, \mathrm{TOA}}$

where $F_{A, N A}=(F \downarrow-F \uparrow)_{A, N A}$, is the net flux with aerosol and without aerosol respectively.

For the atmosphere, the ARF is the difference between that at the TOA and at surface. Precisely:

$\mathrm{ARF}_{\mathrm{ATM}}=\mathrm{ARF}_{\mathrm{TOA}}-\mathrm{ARF}_{\mathrm{SRF}}$.

The SBDART model was used for the estimation of mean ARF for the two boxes over Land and Ocean during both BFA and BNFA conditions. Owing to the interference due to deep clouds during active phases, the retrieval of AOD could be contaminated over the continental region 

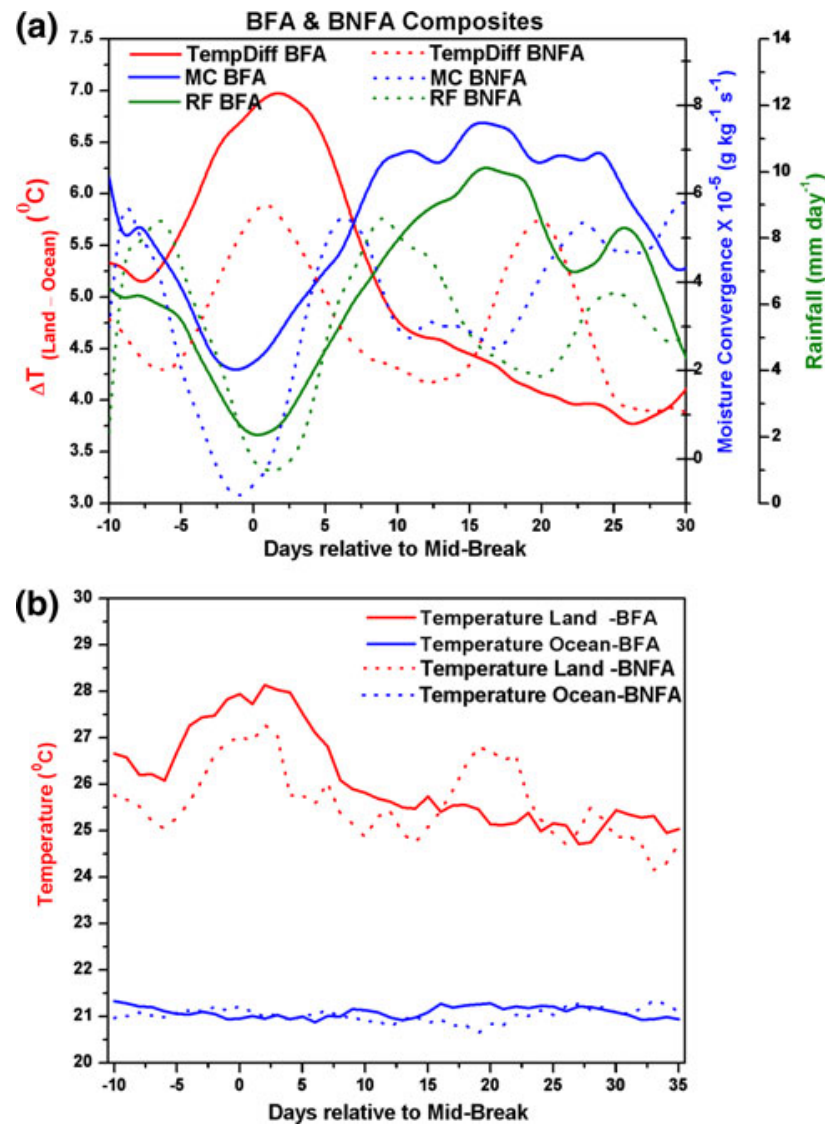

Fig. 9 a Composites of time evolution of temperature difference at $925 \mathrm{hPa}$ between Land and Ocean, moisture convergence and rainfall w.r.t. the mid-day of BFA breaks and BNFA composites. b Time evolution of actual temperature at $925 \mathrm{hPa}$ over Land and Ocean w.r.t. the mid-day of BFA breaks and BNFA composites

and hence the aerosol forcing estimates have not been done during the same period. As the detailed informations regarding the spectral variation of all aerosol-related parameters were not available over the whole region under study, the radiative forcing calculations were carried out at a wavelength of $0.55 \mu \mathrm{m}$ with area averaged aerosol and complementary input parameters. The composite ARF and heating rates were computed at $1 \mathrm{~h}$ interval and integrated over $24 \mathrm{~h}$ to get the mean values.

For the estimation of ARF, the daily mean values of AOD, TCO and PWC were provided. AOD and PWC were obtained from the MODIS site whereas TCO was obtained from TOMS as well as OMI satellites. The area averaged SSA and ASP for both the Land and Ocean regions were obtained from the GADS package (as described by Koepke et al. 1997) and a model Tropical Atmosphere was assumed (McClatchey et al. 1972) with surface albedo from model fixed values for Land and Oceanic regions. Though we expect the atmosphere to be clear during canonical break phases, there could be remnants of clouds in the region under consideration and hence it is mandatory to consider the effects of clouds while estimating the aerosol forcing. In order to account for clouds, we have used the mean cloud conditions such as cloud base height, top height, cloud optical depth and cloud effective radius during both types of breaks under consideration. These cloud parameters except effective radius were obtained from the CloudAerosol Lidar and Infrared Pathfinder Satellite Observation (CALIPSO) satellite-derived cloud layer data (Level 2) from the URL-http://eosweb.larc.nasa.gov/PRODOCS/ calipso/table_calipso.html. Since CALIPSO data is not available prior to 2006, all available data sets such as cloud top pressure and cloud top temperature from MODIS and cloud base from Radiosonde ascents were used to get the mean cloud information during the cases prior to 2006 . The data for cloud effective radius was obtained from the MODIS website. This model (SBDART) accounts for multiple scattering in a vertically inhomogeneous nonisothermal plane-parallel atmosphere as has been discussed in the paper by Ricchiazzi et al. (1998). The output parameters that have been used in this study are the downward and upward SW flux at surface and TOA, plus the atmospheric heating rates at different altitudes.

The estimated values show that the ARF varied over a relatively broader scale during the individual BFA and BNFA cases. Table 1 provides a detailed list of the ARF for the two break types for the corresponding Land and Ocean regions. From the table values, it is clear that the ARF for the individual BFA at the surface for the Land region ranged from -39.51 to $-91.96 \mathrm{~W} \mathrm{~m}^{-2}$ (with mean value of $-59.6 \pm 21.08 \mathrm{~W} \mathrm{~m}^{-2}$ ) and for BNFA cases, it varied between -28.18 and $-27.25 \mathrm{~W} \mathrm{~m}^{-2}$ with mean value of $27.66 \pm 0.48 \mathrm{~W} \mathrm{~m}^{-2}$. The mean TOA forcing over Land for BFA and BNFA cases are $10.67 \pm 3.49$ and $-18.76 \pm 1.48 \mathrm{~W} \mathrm{~m}^{-2}$, respectively. Thus the atmospheric forcing was very much higher (70.27 \pm $24.49 \mathrm{~W} \mathrm{~m}^{-2}$ ) for BFA as compared to a value of $8.90 \pm 1.35 \mathrm{~W} \mathrm{~m}^{-2}$ during BNFA case. This mean value over the Land region during BFA is almost comparable to a similar value $\left(+71.0 \mathrm{~W} \mathrm{~m}^{-2}\right)$ obtained by Tripathi et al. (2005) for an urban location Kanpur situated in the IGP region, but for the winter season in 2004. The mean atmospheric forcing over the Ocean region during both BFA and BNFA were negligibly small compared to the corresponding values over Land region. Hence, the major contribution in the north-south asymmetry arises due to the dominant Land component. Hence our attention is mainly confined to the box over Land. Our estimated value of atmospheric forcing suggests the significant role played by relatively high absorbing type of aerosols during BFA periods over the mentioned region. From the above statistics of ARF over both Land and Oceanic regions, it is clear that there exists a significant north-south gradient of 
heating of the atmosphere during BFA rather than BNFA. To examine how the aerosols heat up the different layers of the atmosphere, the heating rates (HR) were also estimated besides the forcing calculations. Since the heating over the Ocean region is significantly small as compared to that over Land, the difference between the two regions approximately look similar to the Land component itself. Hence, the composite of Land minus Ocean values of heating for both BFA and BNFA is shown plotted in Fig. 10. Both over Land and Ocean, the vertical distributions of HR show a decreasing trend in the lower atmosphere up to about $2-3 \mathrm{~km}$ with a slope remaining approximately constant towards upper altitudes. The important point to be noted, however, is the many-fold increase in HR in the lower atmosphere during BFA as compared to that during BNFA. The value of HR for Land minus Ocean shows about $2.12 \mathrm{~K} /$ day at the surface during BFA against a value of $0.26 \mathrm{~K} /$ day during BNFA. The heating rate integrated up to $3 \mathrm{~km}$ during $\mathrm{BFA}$ is 1 . $05 \mathrm{~K} /$ day and that during BNFA is $0.12 \mathrm{~K} /$ day. The difference between the HR values at surface over the two regions during BFA yields $\sim 2.12 \mathrm{~K} /$ day for the atmosphere. This difference is comparable to the HR over the land itself. The many-fold increase in atmospheric heating during BFA with regard to BNFA can have a relative potential influence on the associated dynamics.

The HR profile obtained by the above methodology during both types of break spells may now be compared with the corresponding vertical distribution of temperature anomaly (Fig. 6a) in the Sect. 3.3.1. Both the profiles during BFA show a clear signature of warming nearly up to $2-3 \mathrm{~km}$. In both the profiles, the lower atmosphere which is bounded by the Land to the north and Ocean to the south experiences a net north-south gradient of warming, part of which could be explained based on the heating generated due to the aerosol forcing.

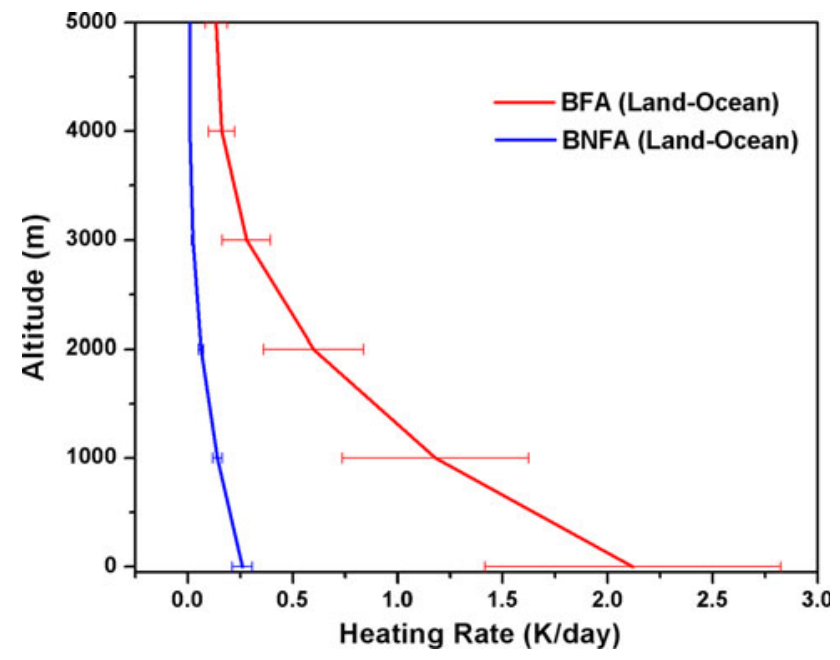

Fig. 10 Vertical profile of difference of aerosol-induced heating rate over Land and Ocean during BFA break and BNFA cases. The crossbars in the figure show the standard deviations for the cases considered

\section{Summary and conclusions}

An aspect of event-to-event variability of monsoon intraseasonal oscillations (MIOs) is that while some long breaks (longer than 7 days) are followed by active spells, there are many similar long breaks that are not followed by active spells. During the summers when (2000-2009), there were six long breaks followed by sustained active conditions (BFA cases) while there were three other long breaks that were not followed by sustained active conditions (BNFA cases). In this study, we identify the dynamical and thermodynamical differences between the two types of breaks and unravel a mechanism responsible for transition to active spells during BFA cases and lack of it during BNFA cases. It is found that a major difference between these two types of long breaks is much larger amount of absorbing
Table 1 Composite aerosol radiative forcing for both $\mathrm{BFA}$ and BNFA breaks

\begin{tabular}{|c|c|c|c|c|}
\hline Cases & Forcing for & $\operatorname{Maximum}\left(\mathrm{W} \mathrm{m}^{-2}\right)$ & $\operatorname{Minimum}\left(\mathrm{W} \mathrm{m}^{-2}\right)$ & Mean $\pm \mathrm{SD}\left(\mathrm{W} \mathrm{m}^{-2}\right)$ \\
\hline \multirow[t]{3}{*}{ BFA Land } & TOA & 16.24 & 7.08 & $10.67 \pm 3.49$ \\
\hline & SRF & -91.96 & -39.51 & $-59.60 \pm 21.08$ \\
\hline & ATM & 108.20 & 46.60 & $70.27 \pm 24.49$ \\
\hline \multirow[t]{3}{*}{ BFA Ocean } & TOA & -14.94 & -4.46 & $-9.62 \pm 3.39$ \\
\hline & SRF & -20.93 & -5.38 & $-13.17 \pm 5.01$ \\
\hline & ATM & 5.99 & 0.92 & $3.55 \pm 1.62$ \\
\hline \multirow[t]{3}{*}{ BNFA Land } & TOA & -19.90 & -17.08 & $-18.76 \pm 1.48$ \\
\hline & SRF & -28.18 & -27.25 & $-27.66 \pm 0.48$ \\
\hline & ATM & 10.45 & 7.96 & $8.90 \pm 1.35$ \\
\hline \multirow[t]{3}{*}{ BNFA Ocean } & TOA & -7.84 & -5.71 & $-6.53 \pm 1.15$ \\
\hline & SRF & -8.70 & -6.36 & $-7.48 \pm 1.18$ \\
\hline & ATM & 1.34 & 0.65 & $0.95 \pm 0.35$ \\
\hline
\end{tabular}


aerosols over CI during BFA cases compared to the BNFA cases. We use these examples of long breaks to investigate a significant role of absorbing aerosols in the modulation of the active-break cycles of MISO, not recognized so far.

The composite anomaly of AOD during BFA cases at two representative locations, namely, over land over CI $\left(75^{\circ}-92^{\circ} \mathrm{E}, 22^{\circ}-28^{\circ} \mathrm{N}\right)$ and over equatorial Indian Ocean $\left(50-95^{\circ} \mathrm{E}, 5^{\circ} \mathrm{S}-7^{\circ} \mathrm{N}\right)$ show a dipole pattern with opposite signs during both active and break phases. The sign of the anomaly over the two locations change alternatively during the transition. For break period, the difference of vertical temperature anomalies is positive up to about $700 \mathrm{hPa}$ with maximum at around $925 \mathrm{hPa}$. The aerosol radiative forcing estimated for the atmosphere over the Land during BFA and BNFA break conditions exhibits clear-cut demarcation. The estimated forcing for the atmosphere over the Land during BFA is $70.27 \pm 24.49 \mathrm{~W} \mathrm{~m}^{-2}$ with a mean heating rate (the difference between Land and Ocean integrated up to $3 \mathrm{~km}$ ) of $1.05 \mathrm{~K} /$ day. Corresponding values during BNFA case was $8.90 \pm 1.35 \mathrm{~W} \mathrm{~m}^{-2}$ and $0.12 \mathrm{~K} /$ day respectively. The HR profiles obtained for Land minus Ocean conditions resemble in pattern to the difference of vertical profile temperature anomalies for the same condition, in particular for the lower atmosphere extending up to $2-3 \mathrm{~km}$. This also provides insight into the considerable role of aerosols in the atmospheric thermodynamic response and transition from break to active conditions.

Together with the lower atmospheric warming, the absorbing aerosols also cool the surface. How is the stabilizing effect of this thermodynamic process overcome for transition to active conditions? Significant north-south gradient of lower atmosphere temperature during BFA cases produces moisture convergence (MC) to CI. Interestingly, it is seen that the MC starts building up immediately after the peak of temperature difference and it is maximum towards the middle of active condition. This large scale MC is enhanced by the spatial gradient of atmospheric heating rate that was induced by a spatial asymmetry of aerosol loading. To overcome the stability achieved by surface cooling due to aerosols, the asymmetric forcing rendered a major contribution. The moist instability of the atmosphere examined with the vertical gradient of equivalent potential temperature suggests that unstable conditions could exist thanks to the large inflow of low-level MC to the CI region. As a result, convection could be triggered in a moist atmosphere. Thus the radiative effects of aerosols could produce a dynamic response in the atmosphere thereby inducing a transition from the break phase to an active spell. This aerosol induced transition from break to active condition on intraseasonal time scale has some similarity to the elevated heat pump mechanism proposed by Lau and Kim (2006) and Lau et al. (2006) on monthly and longer timescales.
The seminal role of absorbing aerosols in the transition emerges from the fact that while AOD is only marginally reduced during BNFA cases, the absorbing type aerosols (AI index) is only one quarter of the same during BFA cases. High concentration of absorbing aerosols during BFA cases is due to the fact that circulation during these periods not only transport more dust aerosols from desert regions, but also allows it to be built up over CI. On the other hand, during BNFA cases, the circulation is such that not only there is little transport of desert aerosols, but also the outward transport from CI does not allow it to build up. Our analysis of the circulation and convection anomalies during the two types of breaks reveals that an organized convection anomaly over the eastern India, Myanmar and south-western China during the BNFA cases is responsible for the lack of accumulation of absorbing aerosols over CI during these episodes and hence responsible for non-transition to an active spell.

The fact that the breaks with large amount of absorbing aerosols over CI go over to active spells while those with low amount of the same do not, indicates a fundamental role played by the aerosols on maintenance of the characteristics (periodicity, amplitude etc.) of the monsoon intraseasonal oscillations (MISO). While the aerosol heating of the lower atmosphere between 1 and $3 \mathrm{~km}$ appears to be crucial from transition of a long break to an active spell, the aerosols themselves are brought in and accumulated by the circulation. Therefore, an interaction between circulation and aerosols is an integral part of observed MISOs. This clearly indicates the need for including aerosol transport and their radiative effects in models attempting to simulate and predict the MISOs.

The aerosol indirect (Twomey) effect, which could lead to suppression of rainfall, was overcome in all the BFA cases due to the convergence of moisture and consequently the ample availability of water content. Therefore, the opposing effect of indirect forcing of the aerosols could be nullified in the BFA cases due to strong meridional gradient of temperature. However, during BNFA cases, it could be also a contributing factor for non transition to an active spell due to weak moisture convergence. Thus our analysis unravels a new and fundamental way in which absorbing aerosols could influence the characteristics of MISOs. However, the number of cases used in composites of aerosol parameters during BNFA is rather small due to lack of such datasets. Therefore it will be desirable to establish the robustness of our results using large number of samples. For accurate quantification and assessing the role of individual aerosol species on the monsoon climate, it is indispensable that reliable and high spatio-temporal data of optical and physico-chemical properties of the aerosols and other geophysical parameters be available for the scientific researchers. 
Acknowledgments The authors wish to acknowledge Dr. A. K. Sahai for the help rendered in processing the data and Ms. Susmitha Joseph for lending hand in the analysis of data at various stages. Dr. G. Pandithurai, Dr. Thara Prabhakaran and Mr. S. Dipu helped in the radiative transfer calculations. One of the authors (MGM) is thankful to the Council of Scientific and Industrial Research (CSIR), Government of India for awarding research fellowship. We thank two anonymous reviewers whose comments on an earlier version of the paper led to substantial improvement of the paper.

\section{References}

Babu SS, Satheesh SK, Moorthy KK (2002) Aerosol radiative forcing due to enhanced black carbon at an urban site in India. Geophys Res Lett 29(18):1880. doi:10.1029/2002GL015826

Bhawar RL, Devara PCS (2010) Study of successive contrasting monsoons (2001-2002) in terms of aerosol variability over a tropical station Pune, India. Atmos Chem Phys 10:29-37

Bollasina M, Nigam S, Lau K-M (2008) Absorbing aerosols and summer monsoon evolution over south Asia: an observational portrayal. J Clim 21:3221-3239

Chakraborty A, Satheesh SK, Nanjundiah RS, Srinivasan J (2004) Impact of absorbing aerosols on the simulation of climate over the Indian region in an atmospheric general circulation model. Ann Geophys 22:1421-1434

Charlson RJ, Schwartz SE, Hales JM, Cess RD, Coakley JA, Hansen JE, Hofmann DJ (1992) Climate forcing by anthropogenic aerosols. Science 255:423-430

Chattopadhyay R, Sahai AK, Goswami BN (2008) Objective identification of nonlinear convectively coupled phases of monsoon intraseasonal oscillation: implications for prediction. J Atmos Sci 65:1549-1569

Collier JC, Zhang GJ (2009) Aerosol direct forcing of the summer Indian monsoon as simulated by the NCAR CAM3. Clim Dyn 32:313-332. doi:10.1007/s00382-008-0464-9

d'Almedia GA, Koepke P, Shettle EP (1991) Atmospheric aerosols: global climatology and radiative characteristics. Deepak Publishing, Hampton

Devara PCS, Raj PE, Pandithurai G, Dani KK, Maheskumar RS (2003) Relationship between lidar-based observations of aerosol content and monsoon precipitation over a tropical station, Pune, India. Meteorol Appl 10:253-262

Goswami BN (2005) South Asian monsoon. In: Lau WKM, Waliser DE (eds) Intraseasonal variability in the atmosphere-ocean climate system, chap 2, pp 19-61

Goswami BN, Ajaya Mohan RS (2001) Intraseasonal oscillations and interannual variability of the Indian summer monsoon. J Clim 14:1180-1198

Goswami BN, Xavier PK (2003) Potential predictability and extended range prediction of Indian summer monsoon breaks. Geophys Res Lett 30(18):1966. doi:10.1029/2003GL017810

Goswami BN, Ajaya Mohan RS, Xavier PK, Sengupta D (2003) Clustering of low pressure systems during the Indian summer monsoon by intraseasonal oscillations. Geophys Res Lett 30(8):1431. doi:10.1029/2002GL016734

Gruber A, Kruger AF (1984) The status of the NOAA outgoing longwave radiation dataset. Bull Am Meteorol Soc 65:958-962

Holton JR (2004) An introduction to dynamic meteorology. Elsevier, USA

Hsu NC, Herman JR, Gleason JF, Torres O, Seftor CJ (1999) Satellite detection of smoke aerosols over a snow/ice surface by TOMS. Geophys Res Lett 26:1165-1168. doi:10.1029/1999GL900155

Huffman GJ, Adler RF, Morrissey M, Bolvin DT, Curtis S, Joyce R, McGavock B, Susskind J (2001) Global precipitation at one- degree daily resolution from multi-satellite observations. J Hydrometeorol 2:36-50

Jai Devi J, Tripathi SN, Gupta T, Singh BN, Gopalakrishnan V (2010) Aerosol radiative impacts over Indian CTCZ region: results from pilot 2008 aircraft experiment. In: Proceedings of Indian Aerosol Science and Technology Association (IASTA-2010), pp 363-364

Jayaraman A (2001) Aerosol radiation cloud interactions over the tropical Indian Ocean prior to the onset of the summer monsoon. Curr Sci 81(11):1437-1445

Jones C, Carvalho LMV, Higgins RW, Waliser DE, Schemm K-KE (2004) A statistical forecast model of tropical intraseasonal convective anomalies. J Clim 17:2078-2095

Joseph S, Sahai AK, Goswami BN (2009) Eastward propagating MJO during boreal summer and Indian monsoon droughts. Clim Dyn 32:1139-1153. doi:10.1007/s00382-008-0412-8

Kalnay E, Kanamitsu M, Kistler R, Collins W, Deaven D, Gandin L, Iredell M, Saha S, White G, Woollen J, Zhu Y, Chelliah M, Ebisuzaki W, Higgins W, Janowiak J, Mo KC, Ropelewski C, Wang J, Leetmaa A, Reynolds R, Jenne R, Joseph D (1996) The NCEP/NCAR 40-year reanalysis project. Bull Am Meteorol Soc 77:437-471

Koepke P, Hess M, Schult I, Shettle EP (1997) Global aerosol dataset. Max-Plank-Institut für Meteorologie Report 243, 44 pp

Lau K-M, Kim K-M (2006) Observational relationships between aerosol and Asian monsoon rainfall, and circulation. Geophys Res Lett 33:L21810. doi:10.1029/2006GL027546

Lau K-M, Kim MK, Kim KM (2006) Asian summer monsoon anomalies induced by aerosol direct forcing: the role of the Tibetan Plateau. Clim Dyn 26:855-864

Maloney ED, Hartmann DL (2000) Modulation of eastern north Pacific hurricanes by the Madden-Julian Oscillation. J Clim 13:1451-1460

McClatchey RA, Fenn RW, Selby JEA, Volz FE, Garing JS (1972) Optical properties of the atmosphere, 3rd edn. Environ Res Pap 411:108. AFCRL-72-0497

Meehl GA, Arblaster JM, Collins WD (2008) Effects of black carbon aerosols on the Indian monsoon. J Clim 21:2869-2882. doi: 10.1175/2007JCLI1777.1

Menon S (2004) Current uncertainties in assessing aerosol effects on climate. Annu Rev Environ Resour 29:1-30. doi:10.1146/ annurev.energy.29.063003.132549

Menon S, Hansen JE, Nazarenko L, Luo Y (2002) Climate effects of black carbon aerosols in China and India. Science 297:2250 2253. doi:10.1126/science.1075159

Mo KC (2001) Adaptive filtering and prediction of intraseasonal oscillations. Mon Weather Rev 129:802-817

Pandithurai G, Pinker RT, Takamura T, Devara PCS (2004) Aerosol radiative forcing over a tropical urban site in India. Geophys Res Lett 31:L12107. doi:10.1029/2004GL019702

Pandithurai G, Dipu S, Dani KK, Tiwari S, Bisht DS, Devara PCS, Pinker RT (2008) Aerosol radiative forcing during dust events over New Delhi, India. J Geophys Res 113:D13209. doi: 10.1029/2008JD009804

Rahul PRC, Salvekar PS, Devara PCS (2008) Aerosol optical depth variability over Arabian Sea during drought and normal years of Indian monsoon. Geophys Res Lett 35:L22812. doi: 10.1029/2008GL035573

Rahul PRC, Salvekar PS, Devara PCS, Sahu BK (2009) An aerosol dipole event over the tropical Indian Ocean during 2006. IEEE Geosci Remote Sens Lett 7:291-295. doi:10.1109/LGRS2009. 203394

Rajeevan M, Gadgil S, Bhate J (2010) Active and break spells of the Indian summer monsoon. J Earth Syst Sci 119(3):229-247

Ramanathan V, Carmichael G (2008) Global and regional climate changes due to black carbon. Nat Geosci 1:221-227 
Ramanathan V, Ramana MV (2005) Persistent, widespread, and strongly absorbing haze over the Himalayan foothills and the Indo-Gangetic Plains. Pure Appl Geophys 162:1609-1626. doi: 10.1007/s00024-005-2685-8

Ramanathan V, Crutzen PJ, Lelieveld J, Mitra AP, Althausen D, Anderson J, Andrea MO, Cantrell W, Cass GR, Chung CE, Clarke AD, Coakley JA, Collins WD, Conant WC, Dulac F, Heintzenberg J, Heymsfield AJ, Holben B, Howell S, Hudson J, Jayaraman A, Kiehl JT, Krishnamurti TN, Lubin D, McFarquhar G, Novakov T, Ogren JA, Podgorny IA, Prather K, Priestley K, Prospero JM, Quinn PK, Rajeev K, Rasch P, Rupert S, Sadourny R, Satheesh SK, Shaw GE, Sheridan P, Valero FPJ (2001) Indian Ocean experiment: an integrated analysis of the climate forcing and effects of the great Indo-Asian haze. J Geophys Res 106(D22):28371-28398

Ramanathan V, Chung C, Kim D, Bettge T, Buja L, Kiehl JT, Washington WM, Fu Q, Sikka DR, Wild M (2005) Atmospheric brown clouds: impacts on south Asian climate and hydrological cycle. Proc Nat Acad Sci 102(15):5326-5333

Ravi Kiran V, Rajeevan M, Vijaya Bhaskara Rao S, Prabhakara Rao N (2009) Analysis of variations of cloud and aerosol properties associated with active and break spells of Indian summer monsoon using MODIS data. Geophys Res Lett 36:L09706. doi: 10.1029/2008GL037135

Rengarajan R, Sarin MM, Sudheer AK (2007) Carbonaceous and inorganic species in atmospheric aerosols during wintertime over urban and high-altitude sites in North India. J Geophys Res 112:D21307. doi:10.1029/2006JD008150

Ricchiazzi P, Yang S, Gautier C, Sowle D (1998) SBDART: a research and teaching software tool for plane-parallel radiative transfer in the Earth's atmosphere. Bull Am Meteorol Soc 79:2101-2114

Rosenfeld D (2000) Suppression of rain and snow by urban and industrial air pollution. Science 287:1793-1796. doi:10.1126/ science.287.5459.1793
Tare V, Tripathi SN, Chinnam N, Srivastava AK, Dey S, Manar M, Kanawade VP, Agarwal A, Kishore S, Lal RB, Sharma M (2006) Measurements of atmospheric parameters during Indian Space Research Organization Geosphere Biosphere Program Land Campaign II at a typical location in the Ganga Basin: 2. chemical properties. J Geophys Res 111:D23210. doi:10.1029/ 2006JD007279

Tripathi SN, Dey S, Tare V (2005) Aerosol black carbon radiative forcing at an industrial city in northern India. Geophys Res Lett 32:L08802. doi:10.1029/2005GL022515

Tripathi SN, Tare V, Chinnam N, Srivastava AK, Dey S, Agarwal A, Kishore S, Lal RB, Manar M, Kanawade VP, Chauhan SSS, Sharma M, Reddy RR, Gopal KR, Narasimhulu K, Reddy LSS, Gupta S, Lal S (2006) Measurements of atmospheric parameters during Indian Space Research Organization Geosphere Biosphere Program Land Campaign II at a typical location in the Ganga Basin: 1. physical and optical properties. J Geophys Res 111:D23209. doi:10.1029/2006JD007278

Waliser DE (2006) Predictability of tropical intraseasonal variability. In: Palmer T, Hagedorn R (eds) Predictability of weather and climate. Cambridge University Press, pp 718

Waliser DE, Jones C, Schemm JK, Graham NE (1999) A statistical extended-range tropical forecast model based on the slow evolution of the Madden-Julian Oscillation. J Clim 12:19181939

Waliser DE, Stern W, Schubert S, Lau KM (2003) Dynamic predictability of intraseasonal variability associated with the Asian summer monsoon. Q J R Meteorol Soc 129:2897-2925

Webster PJ, Hoyos C (2004) Prediction of monsoon rainfall and river discharge variability on 15-30 day time scales. Bull Am Meteorol Soc 85:1745-1765

Xavier PK, Goswami BN (2007) Analog method for real-time forecasting of summer monsoon subseasonal variability. Mon Weather Rev 135:4149-4160 